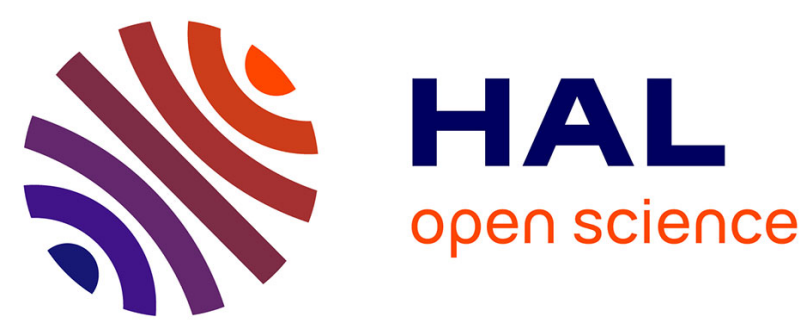

\title{
Systematics and evolution of the libyan jird based on molecular and morphometric data
}

\author{
Malahat Dianat, Jamshid Darvish, Mansour Aliabadian, Roohollah \\ Siahsarvie, Boris Krystufek, Violaine Nicolas
}

\section{- To cite this version:}

Malahat Dianat, Jamshid Darvish, Mansour Aliabadian, Roohollah Siahsarvie, Boris Krystufek, et al.. Systematics and evolution of the libyan jird based on molecular and morphometric data. Journal of Zoological Systematics and Evolutionary Research, 2020, 58 (1), pp.439-458. 10.1111/jzs.12335 . hal-02380626

\section{HAL Id: hal-02380626 \\ https://hal.science/hal-02380626}

Submitted on 5 Dec 2019

HAL is a multi-disciplinary open access archive for the deposit and dissemination of scientific research documents, whether they are published or not. The documents may come from teaching and research institutions in France or abroad, or from public or private research centers.
L'archive ouverte pluridisciplinaire HAL, est destinée au dépôt et à la diffusion de documents scientifiques de niveau recherche, publiés ou non, émanant des établissements d'enseignement et de recherche français ou étrangers, des laboratoires publics ou privés. 


\title{
Systematics and evolution of the libyan jird based on molecular and morphometric data
}

\author{
Malahat Dianat1 | Jamshid Darvish1 | Mansour Aliabadian1 | Roohollah Siahsarvie1,2 | \\ Boris Krystufek3 | Violaine Nicolas4
}

1Department of Biology, Faculty of Science, Ferdowsi University of Mashhad, Mashhad, Iran 2Rodentology Research Department, Institute of Applied Zoology, Faculty of Sciences, Ferdowsi University of Mashhad, Mashhad, Iran 3Slovenian Museum of Natural History, Ljubljana, Slovenia 4Institut de Systematique, Evolution, Biodiversite, ISYEB-UMR 7205-CNRS, MNHN, UPMC, EPHE, Museum National d'Histoire Naturelle, Sorbonne Universites, Paris, France

\begin{abstract}
The libyan jird is one of the most widely distributed species among wild rodents, with its range extending from Morocco to China. Fifteen subspecies were described but their validity and the phylogenetic relationships among them are uncertain. Based on a comprehensive sampling, this study aims to define subspecies limits within Meriones libycus and to discuss the factors driving subspecific diversification. We used an integrative approach combining molecular (Cytochrome b and Cytochrome Oxidase Subunit 1 genes) and geometric morphometric data. Genetic data allowed us to identify three allopatric lineages within $M$. libycus: Western lineage in North Africa, Central lineage in Saudi Arabia, Jordan, and Syria, and Eastern lineage in Iran, Afghanistan, and China. These three lineages can also be differentiated based on skull morphology. Our results support the existence of at least three subspecies within the libyan jird: Meriones libycus libycus, M. l. syrius, and Meriones libycus erythrourus. Based on our divergence time estimates, all divergence events within M. libycus probably occurred during the Pleistocene, after 1.597 Ma. Quaternary climate fluctuations in the Sinai Peninsula explain the differentiation between the African M. l. libycus and the Levant-Arabian M. l. syrius. The differentiation of M. l. syrius with respect to the eastern $M . l$. erythrourus is putatively linked to the climatic fluctuations and tectonic activity of the Zagros Mountains and/or the Mesopotamia Plain of Iraq during the Pleistocene.
\end{abstract}

\section{K E Y W O R D S}

morphometry, mtDNA, phylogeny, Pleistocene, rodent

\section{1 | INTRODUCTION}

The libyan jird, Meriones libycus Lichtenstein, 1823, is one of the most widely distributed species among rodents, ranging across nearly the entire Palearctic Desert Belt from Morocco in Northwest Africa to China (Pavlinov, Lissovsky, \& Obolenskaya, 2010). It occupies desert and semi-desert habitats, generally in areas with stabilized dunes. It becomes most abundant in unflooded river plains and it is often found close to wadies and dayas, and occasionally in arable land (Granjon, 2016). Fifteen subspecies were described within this species (Figure 1): Meriones libycus libycus Lichtenstein, 1823, M. l. erythrourus Gray, 1842, M. l. caucasius Brandt 1855, M. l. eversmanni Bogdanov 1889, M. l. turfanensis Satunin 1903, M. l. aquilo Thomas, 1912, M. l. syrius Thomas 1919, M. l. maxeratis Heptner, 1933, M. l. marginiae Heptner, 1933, M. l. oxianus Heptner, 1933, M. l. sogdianus Heptner, 1933, M. l. afghanus Pavlinov 1987, M. l. farsi Schlitter and Setzer 1973, M. l. iranensis Goodwin 1939, and M. $l$. arimalius Cheesman \& Hinton, 1924 (Boudet, 2010; Bray, Alagaili, \& Bennett, 2014; Corbet, 1978; Ellerman, 1941; Ellerman \& Morrison-Scott, 1951; Harrison \& Bates, 1991; Kingdon et al., 2013; Kryštufek \& Vohralik, 2001; Pavlinov et al., 2010). While some subspecies are 
reportedly widely distributed (e.g., M. l. libycus, M. l. erythrourus), others have very restricted M. l. marginiae, M. l. oxianus, $M$. l. sogdianus, $M$. l. iranensis). The geographical range of several subspecies is subject to debate, as they seem to be disjunct (e.g., M. $l$. erythrourus, $M$. l. caucasius). A subspecies can be defined as "a collection of populations occupying a distinct breeding range and diagnosably distinct from other such populations, with the crucial caveat that these populations comprise completely fertile individuals; that is, populations are not reproductively isolated from one another" (Patten, 2015). While subspecies are by definition allopatric, this does not seem to be true for all described subspecies of M. libycus.

All M. libycus subspecies were recognized on skull features (skull size, rostrum length, tympanic bulla size, zygomatic arch) or coat colors, and descriptions were often based on few specimens (Cheesman \& Hinton, 1924; Etemad, 1978; Goodwin, 1938; Gray, 1842; Heptner, 1933; Lichtenstein, 1823; Pavlinov \& Rossolimo, 1987; Thomas, 1912). The validity of subspecific taxonomy is under considerable discussion and the phylogenetic relationships among them are uncertain (Bray et al., 2014; Ellerman \& Morrison-scott, 1951; Pavlinov et al., 2010). Subspecies have long been a controversial taxonomic rank. Part of the issue stems from a discrepancy between how subspecies were described historically and some of their modern uses (Zink, Groth, Vazquez-Miranda, \& Barrowclough, 2016). Many subspecies were described from few specimens and few localities, and represented geographic variation in only one or at most a few characters. Consequently, subspecific nomenclature sometimes reflects subjective divisions of single character clines. If the goal of an investigator is simply to find examples of geographic variation, most subspecies could be useful indicators of potential be an evolutionarily significant unit (Moritz, 1994), such as in a phylogenetic, comparative, or biogeographical study, many described subspecies are inappropriate. According to Pavlinov et al., (2010), the libyan jird is divided craniometrically into three principal clusters (the African, the SW-N Caspian, and the "main Asian" clusters), that can conveniently be diagnosable by the ratio of the bullar and the incisive foramina lengths. Tabatabaei Yazdi, Adriaens, and Darvish, (2014) and Tabatabaei Yazdi, Colangelo, and Adriaens, (2015) found significant covariation between auditory bulla shape (and size) in $M$. libycus and several geoclimatic variables. Bray et al., (2014) compared the Cytochrome b $(C y t b)$ genetic sequences of three populations from Tunisia, China, and Arabia. They showed the Arabian lineage (presumably representing M. l. arimalius) as clearly distinct from the Chinese M. l. erythrourus and the Tunisian M. l. syrius. The Tunisian and Chinese haplogroups only differ in few mutations, which do not strongly support their recognition as distinct subspecies (Bray et al., 2014). No molecular study encompassing the whole geographic range of the species was ever carried out.

This study aims to define subspecies limits within $M$. libycus and to discuss the factors driving subspecies diversification within it. To this aim, we used an integrative approach combining molecular and geometric morphometric data, and a comprehensive geographical sampling. The combination of molecular and morphometric data on the same specimens or on specimens coming from geographically close localities should allow us to test whether several distinct evolutionary significant units can be recognized within the libyan jird. For the molecular analyses, we used the Cytb and Cytochrome Oxidase Subunit1 (Coxl) genes, as they are the most widely used phylogenetic relationships and for inferring species boundaries in rodents (Bohoussou et al., 2015; Dianat, Aliabadian, Darvish, \& Akbarirad, 2012; Nicolas et al., 2012). Geometric morphometrics is a statistically powerful and visually effective method for assisting taxonomic analyses (Adams, Rohlf, \& Slice, 2004; Cardini \& Elton, 2009; Zelditch, Swiderski, \& Sheets, 2012). The use of landmark data to quantify the variation in both skull size and shape in mammals is sufficiently powerful to detect even 
subtle variation among samples (Barčiová \& Macholán, 2006; Cardini \& Elton, 2009; Cardini, Jansson, \& Elton, 2007; Macholán, Mikula, \& Vohralík, 2008).

\section{2 | MATERIAL S AND ME THODS 2.1 | Molecular analyses}

\subsection{1 | DNA extraction and amplification}

DNA was extracted from frozen muscles or hearts using a salt method (Bruford, Hanotte, Brokfield, \& Burke, 1992). Two mitochondrial genes, Cytb and Coxl, were amplified using primers L7: 5'-ACT AAT GAC ATG AAA AAT CAT CGT/T3' and H6: 5'-TCT TCA TTT TTG GTT TAC AAG AC-3' (Montgelard, Bentz, Tirard, Verneau, \& Catzeflis, 2002), and VF1d: 5'-TTC TCA ACC AAC CAC AAR GAY ATY GG-3' and VR1d: 5'-TAG ACT TCT GGG TGG CCR AAR AAY CA-3' (Ivanova, Dewaard, \& Hebert, 2006), respectively. These primers amplified 1,140 bp for Cytb gene and 658 bp for Coxl gene. PCR conditions for $C y t b$ and Coxl followed Chevret, Veyrunes, and Britton-Davidian, (2005) and Aliabadian, Kaboli, Prodon, Nijman, and $C y t b$ and eight individuals for $C o x l$ ) were sequenced (Montgelard et al., 2002) and the sequences were submitted to GenBank (Accession Numbers: MH580679MH580695 for Cox1 and MH580696- MH580755 for Cytb, Appendix 1 and Table S1). Few Coxl sequences were used in this study, but we decided to add them because it was interesting to compare them to the sequences from China, North Africa, Saudi Arabia, and Afghanistan available in GenBank. These Coxl sequences were selected in order to cover the genetic diversity observed in the $C y t b$ dataset (at least three specimens per $C y t b$ genetic lineage were selected for Coxl analyses).

\subsection{2 $\mid$ Phylogenetic analysis}

In our phylogenetic analyses, we included both our new sequences and the sequences downloaded from GenBank (altogether: 100 specimens for Cytb and 19 specimens for Coxl; Table S1 and Figure 2). The sequences were aligned automatically with BioEdit (Hall, 1999). Each alignment was then edited by eye. In order to avoid missing data in our alignments, final alignments of $737 \mathrm{bp}$ and $606 \mathrm{bp}$ were retained for the Cytb (Data S1) and Coxl (Data S2) analyses, respectively.

Phylogenetic relationships were estimated by Bayesian inference (MRBAYES, version 3.1, Huelsenbeck \& Ronquist, 2001) and maximum- likelihood analyses (software phyML, Guindon et al., 2010) for each gene separately. For both analyses, we chose the mutation model that best fitted the data according to the Akaike information criterion (Akaike, 1973) using MrModeltest 3.7 (Posada \& Crandall, 2001). We used three heated chains and a single cold chain in all Bayesian (MCMC) analyses and initiated runs with random trees. We conducted two independent MCMC runs with 5 million generations per run. We sampled trees and parameters every 100 generations. We used Tracer version 1.4 (Rambaut, Suchard, Xie, \& Drummond, 2013) to estimate the burn-in length. For each run, the first $25 \%$ of sampled trees were discarded as burn-in. Bayesian posterior probabilities (PP) were used to assess statistical support. For the ML analysis, node support was estimated by bootstrap analysis with 100 replications, and the BIONJ (Gascuel, 1997) distance- based tree was used as the starting tree. Ten taxa were used as outgroups: Meriones chengi (AB381900 for Cytb, KF152978 for Cox1), M. unguiculatus (MH580748 for Cytb and MH580687 for Cox1), M. meridianus (MH580749 for Cytb and MH580688 for Cox1), M. grandis (MH580750 for Cytb and MH580689 for Coxl), M. shawi (MH580751 for Cytb and MH580690 for Coxl), M. rex (MH580752 for Cytb and MH580691 for Cox1), M. persicus (KT949952 for Cytb and MH580692 for Cox1), M. vinogradovi (MH580753 for Cytb and MH580693 for Cox1), M. 
crassus (MH580754 for Cytb and MH580694 for Cox1) and M. tristrami (MH580755 for Cytb and MH580695 for Coxl).

Intraspecific gene evolution cannot always be represented by a bifurcating tree. Rather, population genealogies are often multifurcated, descendant genes coexist with persistent ancestors and recombination events produce reticulate relationships (Posada \& Crandall, 2001). Networking approaches taking into account these population-level phenomena are thus suitable to infer intraspecific gene genealogies. Phylogenetic relationships between haplotypes were also inferred for Cytb and Coxl by constructing networks using the median-joining method available in NETWORK, version 4.500 (Bandelt, Forster, \& Rohl, 1999).

\subsubsection{Divergence time estimates}

Divergence time estimates were inferred using BEAST v.1.8 package (Drummond \& Rambaut, 2007) for the Cytb dataset. We chose the DNA substitution model that best fit the data, according to the Akaike information criterion (Akaike, 1973), using MrModeltest v 3.7 (Posada \& Crandall, 2001). We used a log-normal relaxed molecular clock model (Drummond, Ho, Phillips, \& Rambaut, 2006) and a coalescent Bayesian Skyline tree prior (Drummond, Rambaut, Shapiro, \& Pybus, 2005). We run two independent replicates, each consisting of 60,000,000 generations, with trees sampled every 6,000 generations. These two runs were combined in TRACER version 1.4 (Rambaut et al., 2013), which also provides options for examining effective sample size values (all ESS values were larger than 200, which is considered as adequate, according to the BEAST tutorial) and frequency plots to check that mixing of the MCMC chain was adequate. The majority consensus and PP for each node were calculated from the trees after the first $10 \%$ of the trees were discarded as the "burn-in." Six fossil calibrations (log-normal prior distributions) were used to calibrate the chronogram. The first four calibration points were previously used Dianat, Darvish, Cornette, Aliabadian, and Nicolas, (2017): (a) the Gerbillinae-Deomyinae split based on the first occurrence of Gerbillinae in the Lower Miocene fauna of Saudi Arabia (offset $=15.8$, range $=$ 16.0-23.7); (b) the Lophuromys-Acomys-Deomys split, hence indicating the origin of Acomys, based on the earliest known Acomys fossil from Kenya (offset $=5.2$, range $=5.3$ 29.0); (c) the Meriones-Psammomys-Rhombomys split, hence indicating the origin of Meriones, based on the earliest known Meriones fossil from Kazakhstan in the Pliocene (offset $=2.6$, range $=2.6-5.3$ ); (d) the Gerbillus-Sekeetamys split based on the first occurrence of the genus Gerbillus in Armenia in the Pliocene (offset = 2.6; range = 2.6-5.3). We also added two calibration points recently published by Aghová et al., (2018): (a) the Gerbilliscus-Desmodillus split based on the 8.7 Ma fossil of Abudhabia pakistanensis (offset $=8.01$; range $=8.56-22.78$ ); (b) the 6.1 Ma fossil of Gerbilliscus sp. from the Lemudong'o locality 1 in Kenya used as a stem calibration for the genus Gerbilliscus (offset $=5.34$; range = 5.9-22.6). The following species were used as outgroups (Figure S1): Mus musculus (AB819920), Uranomys ruddi (HM635858), Acomys airensis (AJ012021), A. cahirinus (AJ233953), A. chudeaui (FJ415538), A. cilicicus (AJ233957), A. dimidiatus (AJ233959), A. ignitus (Z96064), A. johannis (HM635823), A. minous (GU046553), A. nesiotes (AJ233952), A. percivali (EF187818), A. russatus (FJ415485), A. spinosissimus (AM409396), A. subspinosus (JN247673), A. wilsoni (EF187799), Deomys ferrugineus (FJ415478), Lophuromys flavopunctatus (EU349754), L. sikapusi (AJ012023), Desmodillus auricularis (AJ851272), Gerbilliscus robustus (AM409374), G. guinea (AJ430562), G. gambianus (JF704125), G. leucogaster (JF704162), Gerbillurus paeba (AJ430557), G. tytonis (AJ430559), Sekeetamys calurus (AJ851276), Gerbillus campestris (AJ851271), G. gerbillus (AJ851269), G. henleyi (JQ753050), G. nanus (JQ753051), G. poecilops (JQ753064), G. simoni (GU356577), G. tarabuli (GU356573), Desmodilliscus braueri (AJ851273), Taterillus 
arenarius (AJ851261), Psammomys obesus (AJ851275), Rhombomys opimus (AJ430556), M. vinogradovi (KU561098), M. grandis (KM581508), M. shawi (KM581620), M. chengi (AB381900), M. crassus (AJ851267), M. meridianus (AJ851268), M. rex (AJ851265), $M$. unguiculatus (AF119264), M. persicus (KT949993), and M. tristrami (KU561099).

\subsubsection{Genetic diversity and structure}

Genetic distances between lineages were calculated using the Kimura 2-Parameter (K2P) model of evolution (Kimura, 1980), as implemented in MEGA v 4.0 (Tamura, Dudley, Nei, \& Kumar, 2007). The choice of this model allowed us to compare our values to those in the literature. Several reference values are available for the $C y t b$ and Cox 1 markers concerning intra- and interspecific divergence values among rodents, so we could test the specific status of each lineage under the genetic species concept.

We estimated several statistics to describe and compare the major lineages recovered from our phylogenetic analyses. The number of polymorphic sites, average number of nucleotide differences, nucleotide diversity, and haplotype diversity were calculated for each lineage using DNASP v5.10 (Librado \& Rozas, 2009).

\section{2 | Geometric morphometric analyses}

Only adult specimens with fully erupted and worn molars were incorporated into the morphological analyses. The ventral sides of 269 skulls (Figure 3, Figure 4, Appendix 2 and Table S1) were photographed using a Leica Z6 macroscope coupled to a Leica DFC420 six-megapixel digital camera. Twenty-five two-dimensional landmarks (Figure 4 and Table S2) were digitized on the images using TpsDig 2.17 (Rohlf, 2013). These landmarks (combination of landmarks of types I, II, and III; Bookstein, 1991) were previously used in several studies focusing on jirds (Dianat et al., 2017; Stoetzel et al., 2017; Tabatabaei Yazdi \& Adriaens, 2011, 2013; Tabatabaei Yazdi, Adriaens, \& Darvish, 2012), but most of these landmarks are not specific to jirds and are standard geometric morphometric landmarks used even in studies conducted at the order-level in rodents (Alhajeri \& Steppan, 2018; Samuels, 2009).

We defined 13 groups ( $n=4-60)$ which are associated with subspecies as defined in earlier studies (Figure 3 and Table S1): Group 1-Afghanistan and a single specimens from Zabol, Iran; Groups 2, 3, and 4-west, east, and central Algeria, respectively; Group 5-northeast Iran along the border of Turkmenistan (M. l. maxeratis); Group 6-east Caspian coast (M. $l$. iranensis); Groups 7 and 10-northeast of Iran; Groups 8, 9, and 11-central, central-east, and southwest Iran, respectively; Group 12 - Jordan and Syria; Group 13-Tunisia.

Landmark configurations were scaled to unit centroid size and superimposed using the partial Procrustes generalized least-squares method in R environment (R Development Core Team, 2018) in accordance with the codes in Claude (2008). Size was computed as centroid size (Bookstein, 1991) and the shape variables were extracted as residual Procrustes coordinates (Gower, 1975; Rohlf, 1990; Rohlf \& Slice, 1990).

In order to explore allometry, a multivariate linear regression was performed on the shape data onto centroid size (Klingenberg, 1998; Monteiro, 1999). Shape variables were calculated as the non-null principal components (PCs) of a PCA performed on the individual shapes variance-covariance matrix (Claude, Pritchard, Tong, Paradis, \& Auffray, 2004; Siahsarvie et al., 2012), and the first 25 PCs (giving more than $90 \%$ of the total shape variation) were applied in the analyses. The correction for the effect of size and shape variation was performed using Burnaby method, and based on the allometric vector of the largest sample for each lineage that is group 4, 9, and 10 (Burnaby, 1966; Claude, 2008). The subsequent morphological analyses on shape were performed using both strategies, with and without 
allometry, in order to check the possible influence of allometry on the ordination of populations.

To test the statistical differences in size and shape among groups, we performed analysis of variance (ANOVA) on centroid size and multivariate analysis of variance (MANOVA) on shape variables, respectively. The significance of the pairwise differences in size and shape were assessed by Tukey's honestly significant differences (HSD) (Mendiburu, 2017) and pairwise permutation MANOVA procedures (Hervé, 2018), respectively. A box plot on centroid size was graphed to display the differences in size among populations. As sexual dimorphism, either attributed to sexual selection or sex-specific natural selection, is one of the main factors driving biodiversity (Moriyama, 2013; Punzalan \& Hosken, 2010), we explored the effect of sex on both size and shape variation of the groups (total number of individuals $n$ $=228$ ) through an ANOVA and MANOVA, respectively. A linear discriminant analysis (LDA) was performed on shape variables using the population factor to explore the morphological similarity among populations. Population with $<10$ specimens (groups 1, 3, 11, and 12) were not included in making the discriminant axesand were a posteriori projected on them. Shape variation along the first two discriminant axes was explored using thin-plate splines (Bookstein, 1989). To highlight the magnitude of overall shape differences among groups, a neighborjoining tree (NJ) based on Procrustes distances was estimated using all shape variables.

In order to assess whether the isolation-by-distance model (Wright, 1943) can explain the pattern of morphometric divergence among populations of libyan jirds, the correlation between interpopulation Procrustes and geographical distance matrices was estimated using a non-parametric Mantel test (Mantel, 1967) with 10,000 Monte Carlo permutations. A similar analysis was performed between the geographical and genetic distance matrices $(C y t b, \mathrm{~K} 2 \mathrm{P})$ to explore the geographical effect on genetic variation. An additional Mantel test was carried out to examine the relationship between morphometric and molecular distances among populations. As the genetic distance was not available for all the corresponding morphometric groups, only 10 groups (groups 1, 2, 5, 7, 8, 9, 10,11, 12, and 13) were considered in the two latter comparisons. For all the three geographical-morphometric, geographical-genetic, and morphometric-genetic comparisons, the scatterplot of pairwise distances was graphed to depict the correlation between low-distant and high-distant groups.

All morphometric statistical analyses were performed using R (R Development Core Team, 2018) and codes in Claude (2008). We used the MASS library (Venables \& Ripley, 2002) to perform LDA, ape library (Paradis, Claude, \& Strimmer, 2004) to perform NJ, Agricolae library (Mendiburu, 2017) for post hoc Tukey HSD test, RVAideMemoire library (Hervé, 2018) for Pairwise Permutation MANOVA and pixmap library (Bivand, Leisch, \& Maechler, 2011) to digitize a template of skull for a more animated visualization of shape variation along the discriminant axes (Claude, 2008). The weighted mean geographic distances between the 13 studied groups were estimated using geosphere library (Hijmans, 2017) and the Mantel test was performed by ade4 library (Dray \& Dufour, 2007).

\section{3 | RESULTS}

\section{1 | Molecular analyses}

No indels or stop codons were observed, suggesting that no nuclear copies of mtDNA were present in the dataset. The mutation model that best fitted the data according to the Akaike information was HKY $+\mathrm{G}$ for Cytb and $\mathrm{HKY}+\mathrm{I}+\mathrm{G}$ for Coxl. The species M. libycus forms a strongly supported monophyletic group (Figure 5). Results of the phylogenetic (Figure 5, Figures S2 and S3) and network analyses (Figure 6) are congruent and highlight the existence 
of several lineages within M. libycus. Three main lineages (I, II, and III) can be identified, but the resolution between lineages is poor. Lineage I is composed of specimens from Saudi Arabia, Jordan, and Syria (for both Cytb and Coxl datasets). Lineage II is composed of specimens from Algeria, Morocco, and Tunisia for the $C y t b$ dataset, and specimens from Algeria and Morocco for the Coxl dataset (no specimen from Tunisia was included in the Coxl dataset). Lineage III is composed of specimens from Iran, Afghanistan, China, and Tunisia for the Cytb dataset, and of specimens from Iran and China for the Coxl dataset (no specimen from Afghanistan and Tunisia was included in the Coxl dataset).

Lineage I corresponds to the subspecies $M$. l. libycus, and lineage II to the subspecies $M$. $l$. syrius. Lineage III contains specimens belonging to the subspecies $M$. l. iranensis, $M$. $l$. maxeratis, M. l. erythrourus, M. l. aquilo, M. l. turfanensis, M. l. libycus (from Tunisia) and all the specimens for which no subspecies name has been reported previously and coming from center and northeast of Iran and Afghanistan. Within this lineage there is no correlation between subspecies names and genetic structure.

The mean percentage of sequence divergence (K2P) between lineages ranges from $8.6 \%$ (between lineage I and II) to $8.9 \%$ (between lineage III and I) for $C y t b$, and between $6.7 \%$ and $9 \%$ for Coxl. Within lineages, the mean percentages of sequence divergence are always lower than $1 \%$ for both genes. Haplotype diversity is high in all lineages (values $>0.941$ for the Cytb gene, and values $>0.833$ for Coxl; Table 1). Nucleotide diversity varies from 0.00787 in lineage I to 0.1051 in lineage III for the Cytb gene, and from 0.00330 for lineage II to 0.00582 in lineage III for the Coxl gene.

The time to the most recent common ancestor (TMRCA) of all M. libycus is estimated to be 1.597 Ma (highest posterior density interval containing 95\% of the sampled values: $0.96-$ 2.354; Figure S1). The TMRCAs for lineages III, II, and I are estimated to be $0.227 \mathrm{Ma}$ (0.107-0.431), ,0.358 Ma (0.128-0.638), and 0.272 Ma (0.095-0.529), respectively.

\section{2 | Geometric morphometrics}

No sexual dimorphism was detected in groups either for size $(F=1.404, p>.2)$ or for shape $(F=1.2083, p>.1)$. This is in agreement with Darvish (2009), and Tabatabaei Yazdi and Alhajeri (2018), who detected no sexual dimorphism in jirds and in libyan jird, respectively. We, therefore, pooled the two sexes for subsequent analyses. There are significant differences both in size $(F=4.716, p=2.22 \times 10-5)$ and shape $(F=2.0936, p=2.2 \times 10-16)$ among the 13 defined groups. Concerning size differences, specimens from the central desert of Iran (group 8) have the biggest skulls, while no significant size difference was detected among the other groups (Table 2, Figure 7). Cranial shape, however, is significantly different among most of the groups (Table 3), indicating that both taxonomic and geographical variation can influence the shape of this structure in libyan jird.

Multivariate linear regression of shape data (the first $25 \mathrm{PCs}$ ) on centroid size is highly significant $(F=216.75, p=2.2 \times 10-16)$, showing that there is allometry in the dataset. Similar results were obtained when the analysis was performed for only the first principal component or with using log-transformed centroid size. This is in contrast with Tabatabaei Yazdi and Alhajeri, (2018) who detected no allometry in cranial shape of M. libycus when they pooled the sexes together. They, however, found a significant allometry for this species when two sexes were regarded separately. Our different result, therefore, can be due to different sex ratio in our samples compared to those studied in Tabatabaei Yazdi and Alhajeri, (2018). The multivariate statistical analyses performed on original data and on allometry-corrected data show very similar results. Here, we only present the latter. The NJ tree analysis and the first axis of the LDA (Figure 8 and Figure 9) shows a good discrimination between groups from Iran (groups 5-11) and Afghanistan (group 1) and those from North Africa (Algeria: groups 2-4; Tunisia: group 13). The former can be differentiated 
from the specimens of North Africa by their smaller tympanic bullae, longer rostrum, smaller braincase, larger foramen magnum, and the intermediate part of the zygomatic arch being less curvated inward (Figure 8). On the first axis of the LDA, specimens from Jordan and Syria (group 12) are morphologically closer to the specimens from Iran and Afghanistan than those of North Africa. However, in the NJ tree, specimens from Jordan and Syria appear quite different from all others specimens. It is because in the discriminant analysis, the Jordan and Syria group was first put out from the analysis and then projected on the axes (because of its small sample size). When the LDA was performed including this group (not shown here), it showed an intermediate position on the first axis, but very distinct morphology on LD2, LD3, LD4, and LD6. Specimens from Iran and Afghanistan show important shape variations on the second axis of LDA. Groups 6, 7, 8, and 10 are characterized by a longer rostrum, longer tooth row and smaller foramen magnum, compared to group 9. Groups 1, 5, and 11 have somewhat intermediate values (Figure 8).

Mantel test showed a significant positive relationship between geographical and morphometric distances $(r=.66, p<.0004)$ and between geographical and genetic distance $(r$ $=.83, p<.0005)$. The same pattern was observed when morphometric and genetic distances were compared $(r=.92, p<.0006)$. Bivariate scatterplots of geographical distances versus morphometric and genetic distances (Figures S4 and S5) confirm a general pattern of positive relationship, but a discontinuity between the lower geographical distances compared to higher ones. The same pattern is seen when one looks at the pairwise biplot of morphometric versus genetic distances (Figure S6). A correlation test between morphology and geography, for low geographical distant (less than 1,500 km) and high geographical distant (more than 3,000 km) groups, separately, showed a positive and negative significant relationship between geographical and morphometric distances, respectively $(r=.51, p<.003$ for low-distant; $r=$ $-.62, p<.0002$ for high-distant groups). For genetic distances, a positive relationship with geographical distances is seen when one looks at less distant groups $(r=.6, p<.004)$. This correlation is, however, not significant for distant groups, that is, North Africa compared to South Asia $(r=-.22, p>.3)$. Morphology and genetics are positively correlated in low-distant populations $(r=.47, p<.03)$ and non-correlated in high-distant groups $(r=.32, p$ $>$.13). In all cases, the group of Jordan and Syria, with having moderate geographical distances to other groups, is genetically and morphologically the most distant.

\section{4 | DISCUSSION}

\subsection{Taxonomic implications}

Our mitochondrial genetic data allowed us to identify three lineages within M. libycus differing by $8.6 \%-8.9 \%$ sequence divergence based on $C y t b$ data. These genetic lineages have an allopatric distribution (Figure 2): lineage I (thereafter called "central lineage") is present in Saudi Arabia, Jordan, and Syria; lineage II ("Western") is present in Algeria, Morocco, and Tunisia, and lineage III ("Eastern”) is present in Iran, Afghanistan, China, and Tunisia. By definition, subspecies are populations not reproductively isolated from one another, thus several authors have advocated that it makes no sense to expect reciprocal monophyly among subspecies, at least with respect to neutral markers. Some nuclear genes under natural selection are expected to differ, given that subspecies characters are assumed to have a genetic basis (Patten, 2015). We agree that finding no difference in neutral markers between populations cannot be used as an argument to say that all these populations belong to the same subspecies. Finding a difference in neutral markers means that sufficient time has elapsed since the sampled populations were isolated. If a difference in the phenotype is also observed between these populations, then they can be considered as distinct subspecies. Due to its 
numerous advantages such as high rate of evolution, lack of recombination and haploidy, mtDNA has been widely used as a classical phylogeographic marker and for subspecies recognition. However, because of its maternal inheritance, the risks of introgression and the absence of independent information coming from unlinked locus, using mtDNA genetic distances only to infer the taxonomic rank of taxa and its phylogeographic history may be misleading (e.g., Bradley \& Baker, 2001; Brito \& Edwards, 2009). Keeping this in mind, the comparison of obtained genetic divergence between lineages with previously published studies can nonetheless give interesting clues. The Cytb genetic distance among species of the genus Meriones ranges from $12.3 \%$ to $20.5 \%$ (Wang, Zhao, Fang, Liao, \& Liu, 2013). Between subspecies, it is 1.4\% in Meriones tamariscinus (Bray et al., 2014), it ranges from $6.7 \%$ to $7.5 \%$ in M. meridianus (Bray et al., 2014) and it ranges from $2.5 \%$ to $9.6 \%$ in $M$. persicus (Dianat et al., 2017). The $C y t b$ genetic distance observed between our three lineages of M. libycus corresponds to those observed between other subspecies of Meriones. Up to 15 subspecies were previously reported (Boudet, 2010; Ellerman, 1941; Ellerman \& Morrison-Scott, 1951; Gromov et al., 1961; Ranck, 1968; Setzer, 1961) based on coat color and cranial characters, but these reports were generally based on few individuals and few localities. One study tried to quantitatively assess the morphometrical variability within $M$. libycus across its entire geographic range (Pavlinov et al., 2010). This study, based on 11 cranio-dental measurements, showed three main groups: a North African group (from Morocco to Egypt), a southwest-north Caspian group (Azerbaijan and Emba River in Kazkhstan), and an Asian group (Iran, Afghanistan, Turkmenistan, Uzbekistan and most Kazakhstan). Tabatabaei Yazdi et al., (2014) and Tabatabaei Yazdi et al., (2015) showed that geoclimatic conditions constrain $M$. libycus tympanic bulla size and shape.

For the first time, we combined genetic and morphometric data for specimens across most of the geographic range on the libyan jird. It is well known that skull morphology in rodents is influenced by climatic factors (Alhajeri, 2019). For example, ventral cranium morphology is associated with climate (Alhajeri, 2018), and aridity is strongly associated with inflation and hypertrophy of tympanic bullae in small mammals (Alhajeri, Hunt, \& Steppan, 2015; Alhajeri \& Steppan, 2018; Colangelo, Castiglia, Franchini, \& Solano, 2010; Mason, 2016; Pavlinov \& Rogovin, 2000; Tabatabaei Yazdi \& Adriaens, 2011; Tabatabaei Yazdi et al., 2012, 2015; Webster \& Webster, 1975), and the same is true for elongation and narrowness of nasal (Alhajeri \& Steppan, 2018; Cortes, Zuleta, \& Rosenmann, 1988; Feldhamer, Drickamer, Vessey, Merritt, \& Krajewski, 2007; Lay, 1972; Ojeda et al., 1999). Specifically for $M$. libycus, tympanic bulla size and shape is mainly correlated with rainfall and temperature (Tabatabaei Yazdi et al., 2014, 2015). Even if we did not specifically test for this association in our study, we believe that the combination of molecular and morphometric data helps to clarify the taxonomy of this species.

1-The Western clade groups all specimens from Algeria and Morocco, and most specimens from Tunisia. Our morphometric analysis also emphasizes the strong similarity between all specimens from Algeria and Tunisia. Based on morphometric data, Pavlinov et al., (2010) also showed that all specimens from North Africa, from Morocco to Egypt, belong to one entity. According to our analyses, these specimens are characterized by their larger tympanic bullae, smaller rostrum, larger braincase, smaller foramen magnum, and the intermediate part of the zygomatic arch which is more curvated inward compared to specimens from Iran, Afghanistan, Jordan and Syria. M. l. libycus was described based on its large tympanic bullae with inflated mastoid and large and broad zygomatic arch (Lichtenstein, 1823). In our genetic analyses several specimens from Tunisia cluster with the eastern clade and not with all others specimens from North Africa, which contradict morphometric and biogeographic results. Problematic Tunisian sequences were extracted from Genbank and no vouchers are available for them. According to Ben Faleh (personal communication), who produced these sequences, 
it is possible that these specimens represent a recent anthropogenic introduction from the eastern clade, as libyan jirds are sometimes sold as pets in Tunisia. We conclude that $M$. $l$. libycus is the appropriate taxonomic name to designate populations from Northern Africa. 2-The Central lineage groups specimens from Syria, Jordan and Saudi Arabia. Our morphometric analyses also showed that these specimens are distinct from all others $M$. libycus; unfortunately no specimen from Saudi Arabia could be included in our morphometric analyses. Pavlinov et al., (2010) mentioned that the specimens from the North of Saudi Arabia (locality of Qaisumah) and Levant (Jordan and Syria) are morphometrically close to each other and distinct from Asian and North African. In previous studies, it was suggested that there are two distinct subspecies on either side of the Euphrates (East: M. l. erythrourus; West: $M$. l. syrius) and a third subspecies in the south of Saudi Arabia and Oman (M. $l$. arimalius) (Harrison \& Bates, 1991). Based on Tabatabaei Yazdi et al., (2015), the specimens from Mesopotamia are characterized by less inflated, more elongated and narrower bulla which is related to the geoclimatic variables. Our genetic data suggest that the name $M$. $l$. syrius should be used for specimens from Syria, Jordan and Northern-central Saudi Arabia, that is, west of the Euphrates. This subspecies was described based on its small tympanic bullae with less inflated meatus (Thomas, 1912). The status of $M$. l. arimalius still needs to be evaluated.

3-The Eastern lineage group specimens from Iran, Afghanistan, China and several specimens from Tunisia (but see our above comment concerning these specimens from Tunisia which may correspond to a recent human introduction). Our geometric morphometric results also emphasized the strong uniformity within this lineage (Figure 8,9 and 8,9). Based on a more extensive sampling, Pavlinov et al., (2010) showed that the specimens from Iran and Afghanistan, are morphometrically close to specimens from Turkmenistan, Uzbekistan, Kazakhstan, Kyrgyzstan and China. Twelve subspecies have been reported for M. libycus in the east of its distribution. We sequenced five of these subspecies (M. l. iranensis, $M$. $l$. aquilo, M. l. maxeratis, M. l. turfanensis and M. l. erythrourus) but could not distinguish them genetically (Figure 6). In our morphometric data, specimens from the geographical ranges of M. l. erythrourus (groups 1, 7, 9), M. l. maxeratis (group 5) and M. l. iranensis (group 6) were present, but are not separated in the LDA (Figure 8) and NJ tree (Figure 9). These three subspecies were described based on skull size, tympanic bullae size, rostrum length, foramen incisive length (Goodwin, 1938; Heptner, 1933), or coat color for M. l. erythrourus (Gray, 1842). However these descriptions were based on few specimens and our morphometric data show that these skull characters cannot be used to discriminate these three subspecies. Our data suggest that all these subspecies should be considered as synonym of M. l. erythrourus. No genetic data is available for the subspecies M. l. caucasius, M. l. eversmanni, $M$. $l$. marginae, M. l. oxianus, M. l. sogdianus, M. l. afghanus and M. l. farsi. In the morphometric study of Pavlinov et al., (2010), four specimens from southwest (Azerbaijan) and north (Emba River in Kazakhstan) of the Caspian Sea were distinct from all others specimens, and were recognized as "Caspian group". Pavlinov et al., (2010) chose the name M. l. eversmanni for those from the north of the Caspian Sea, and M. l. caucasius for specimens of the southwest. In the future it would be interesting to add these specimens in the genetic analyses to further test their subspecific distinctiveness. Based on the study of Pavlinov et al., (2010) it seems likely that the name erythrourus is to be used for all specimens captured in Iran, Afghanistan, Turkmenistan, Uzbekistan, Kyrgyzstan, China, and most of Kazakhstan.

We explored whether the divergence between the population lineages may be due to genetic discontinuity or may simply reflect the geographical distance effect, suggesting an isolation-by-distance model for the divergence among populations. Under this model, one expect that the greater the geographical distance existing between two populations, the more genetically and morphologically distant they will be. This hypothesis is accepted when 
intra-lineage groups are regarded, implying that isolation-by-distance model among the populations of each subspecies (M. l. libycus and M. l. erythrourus) is observed. We only had one small group from the central lineage and could not test the model in that subspecies. This model was not approved for moderate (central lineage distance from other groups) and long (western lineage distances from eastern lineage and vice versa) geographical distant groups, suggesting that a genetic discontinuity may exist between the three lineages.

\section{2 | Phylogeography}

Meriones libycus is widely distributed from Morocco to China, but the climatic niche modeling analysis of Bray et al., (2014) shows that the probability of occurrence of the species is not evenly distributed throughout its range. Three main areas of high probability of occurrence of the species can be identified: one in North Africa from Morocco to Libya, one in the Levant and northern Saudi Arabia, and one from Iran to northwest China. The probability of occurrence is low in Egypt and Sinai, except on a very small stripe on the Mediterranean Coast. The probability of occurrence of this species is also low in Zagros Mountains (Western Iran, North Iraq and South East Turkey) and Mesopotamia (Iraq). Thus, the actual probability of occurrence at least partially explains the observed genetic discontinuities between the three subspecies M. l. libycus, M. l. syrius and M. l. erythrourus. Based on our divergence time estimates all divergence events within M. libycus probably occurred during the Pleistocene, after 1.597 Ma (95\% HPD range: 0.96-2.354 Ma). These values are much lower than those previously recorded by Bray et al., (2014), which obtained divergence of 3.2 Ma. This difference can be explained by the fact that Bray et al., (2014) used as a calibration point the split between Mus and Rattus dated at $16 \mathrm{Ma}$. Several recent studies showed that this split is much more recent (Aghová et al., 2018; Kimura, Hawkins, McDonough, Jacobs, \& Flynn, 2015). The resolution between the three lineages is poor suggesting a rapid diversification event.

A good understanding of the geography of the Arabian Peninsula and the Levant are important to understand diversification within M. libycus. The Arabian Peninsula is bounded on three sides by the Red Sea, the Persian Gulf and the Indian Ocean. The northern area is a vast open steppe that unrolls toward the Mediterranean Sea with no major geographical obstructions (Figure 2). This region played a central role in the history of species movements between Africa and Eurasia, including migrations of modern humans and earlier Homo species (Fernandes, Rohling, \& Siddall, 2006). The main factor affecting migration potential and faunal changes/exchanges between Eurasia and Africa during the Neogene was paleogeography, while after the early Pliocene migrations were mainly controlled by climatic changes (Koufos, Kostopoulos, \& Vlachou, 2005). During the Pleistocene, oscillation of glacial and inter-glacial periods caused not only fluctuations in the distribution of habitats, but also in Red Sea level (reviewed by Ndiaye, Chevret, Dobigny, \& Granjon, 2016). This made the Red Sea sometimes a barrier to dispersal between Africa and the Arabian Peninsula and Asia for various faunas and plants, but at other occasions, it also provided pathways allowing intercontinental exchanges. The two main routes proposed are: (a) through the Sinai Peninsula; or (b) across the Bab-el-Mandeb Strait in the southern Red Sea (Fernandes et al., 2006). Given the actual distribution of the species and the fact that no land bridge has been present for millions of years at the Bab-el-Mandeb Strait (Fernandes et al., 2006), we emphasize the northern route, across the Sinai Peninsula, as the primary connection for $M$. libycus. The western boundary of Sinai is ecologically diverse as is Sinai itself. Routes into, and out of, Sinai are the limiting factors on libyan jird movement. Sinai, at a maximum 210 $\mathrm{km}$ from west to east, is ecologically an extension of the eastern desert of Egypt and its link to the Negev desert (and on the north to the Gaza Strip). The western land "boundary" of Sinai is across a range of habitats: a possible strip of sandy dry land only accessible in glacial periods 
at low sea level of the Mediterranean, marshy areas, lakes Timsah and Great Bitter Lake, several dry land areas. To the south lies the Gulf of Suez, some $315 \mathrm{~km}$ long and 19-32 km wide, with a maximum depth today of 75-80 $\mathrm{m}$ and an average of 40-60 $\mathrm{m}$ in many parts (Derricourt, 2005). Much of the floor of the Gulf would have been exposed during the drier stages of the Pleistocene, extending the access into the Sinai Peninsula from the Eastern Desert, but remaining a flooded barrier during the wetter phases. Thus in climate like today's there is a potential for land crossing out of Africa across three zones totaling $70 \mathrm{~km}$ width. In the wetter periods of the Pleistocene, the coastal strip would not have existed, the marshy areas and lakes would have been fuller, narrowing further the actual access routes between the Eastern Desert and Sinai. Climate fluctuations during the Pleistocene would thus have sometimes favored, and sometimes prevent gene flow between African M. l. libycus and Levant-Arabian M. l. syrius. The differentiation of the Levant-Arabian $M$. $l$. syrius with respect to the eastern $M$. l. erythrourus could be explained by a long independent evolutionary history of these subspecies caused by the ecological barriers of the Zagros Mountains and/or the Mesopotamia Plain of Iraq. The Mesopotamia Plain of Iraq is a very mobile basin of alluvial sediment accumulation (Fouad \& Sissakian, 2011). Due to both neotectonic activity (gradual uplift of the Zagros Mountains) and climate changes, this area was witness, during the Pleistocene, to cyclical activation and shifting of river channels and profound modification of habitats (Fouad \& Sissakian, 2011; Minarjkova, 2003). We sequenced a lot of specimens from Iran but found a low degree of genetic variability in this country, all specimens belonging to the same genetic lineage. This result is similar to what was observed in several others rodent species, such as Apodemus witherbyi (Haddadian Shad, Darvish, \& Pouyan, 2016), and Jaculus blanfordi (Darvish et al., 2016). A very different pattern was observed in another jird, species, M. persicus, Dianat et al., (2017) having observed several allopatric lineages in Iran possibility corresponding to distinct subspecies.

\section{ACKNOWLEDGMENTS}

Part of this work was carried out using resources from the UMS MNHN/ CNRS 2700 "Outils et methodes de la Systematique integrative," and particularly at the "Service de Systematique Moleculaire" and the "Plateau Technique de Morphometrie." Some analyses were performed in the Animal Biosystematic Laboratory of the Ferdowsi University of Mashhad in Iran. An important part of the skull samples was loaned from Darvish Rodents Collection of the Ferdowsi University of Mashhad. Some tissue samples were supported by Slovenian Museum of Natural History. We are grateful to M. Adibi for his help in sampling.

\section{O}

\section{REFERENCES}

Adams, D. C., Rohlf, F. J., \& Slice, D. E. (2004). Geometric morphometrics: Ten years of progress following the 'revolution.' Italian Journal of Zoology, 71(1), 5-16. https://doi.org/10.1080/11250000409356545

Aghová, T., Kimura, Y., Bryja, J., Dobigny, G., Granjon, L., \& Kergoat, G. J. (2018). Fossils know it best: Using a new set of fossil calibrations to improve the temporal phylogenetic framework of murid rodents (Rodentia: Muridae). Molecular Phylogenetics and Evolution, 128, 98-111. https://doi.org/10.1016/j.ympev.2018.07.017 
Akaike, H. (1973). Information theory and ad extension of the maximum likelihood principle, in Petrov, B. N., Csaki, F., 2nd international Symposium on Information Theory, Tsahkadsor, Armenia, USSR, September 2-8, 1971, Budapest: Akademiai Kiado, p. 267-281.

Alhajeri, B. H. (2018). Craniomandibular Variation in the Taxonomically Problematic Gerbil Genus Gerbillus (Gerbillinae, Rodentia): Assessing the Influence of Climate, Geography, Phylogeny, and Size. Journal of Mammalian Evolution, 25(2), 261-276. https://doi.org/10.1007/s10914-016-9377-2

Alhajeri, B. H. (2019). Cranial variation in geographically widespread dwarf gerbil Gerbillus nanus (Gerbillinae, Rodentia) populations: Isolation by distance versus adaptation to local environments. Journal of Zoological Systematics and Evolutionary Research, 57(1), 191-203. https://doi.org/10.1111/jzs.12247

Alhajeri, B. H., Hunt, O. J., \& Steppan, S. J. (2015). Molecular systematics of gerbils and deomyines (Rodentia: Gerbillinae, Deomyinae) and a test of desert adaptation in the tympanic bulla. Journal of Zoological Systematics and Evolutionary Research, 53(4), 312-330. https://doi.org/10.1111/jzs.12102

Alhajeri, B. H., \& Steppan, S. J. (2018). A phylogenetic test of adaptation to deserts and aridity in skull and dental morphology across rodents. Journal of Mammalogy, 99(5), 11971216. https://doi.org/10.1093/jmammal/gyy099

Aliabadian, M., Kaboli, M., Prodon, R., Nijman, V., \& Vences, M. (2007). Phylogeny of Palaearctic wheatears (genus Oenanthe) - Congruence between morphometric and molecular data. Molecular Phylogenetics and Evolution, 42(3), 665-675. https://doi.org/10.1016/j.ympev.2006.08.018

Bandelt, H. J., Forster, P., \& Rohl, A. (1999). Median-joining networks for inferring intraspecific phylogenies. Molecular Biology and Evolution, 16(1), 37-48. https://doi.org/10.1093/oxfordjournals.molbev.a026036

Barčiová, L., \& Macholán, M. (2006). Morphometric study of two species of wood miceApodemus sylvaticus andA. flavicollis (Rodentia: Muridae): traditional and geometric morphometric approach. Acta Theriologica, 51(1), 15-27. https://doi.org/10.1007/BF03192651

Bivand, R., Leisch, F., Maechler, M. (2011). pixmap: Bitmap Images ("Pixel Maps"). R package version 0.4-11, URL http://CRAN.R-project.org/package=pixmap 
Bohoussou, K. H., Cornette, R., Akpatou, B., Colyn, M., Peterhans, J. K., Kennis, J., ... Nicolas, V. (2015). The phylogeography of the rodent genus Malacomys suggests multiple Afrotropical Pleistocene lowland forest refugia. Journal of Biogeography, 42(11), 2049-2061. https://doi.org/10.1111/jbi.12570

Bookstein, F. L. (1989). Principal warps: thin-plate splines and the decomposition of deformations. IEEE Transactions on Pattern Analysis and Machine Intelligence, 11(6), 567585. https://doi.org/10.1109/34.24792

Bookstein, F. L. (1991). Morphometric Tools for Landmark Data: Geometry and Biology. Cambridge U Press, Cambridge, UK, pp 1-435.

Boudet, Ch. (2010). Species Sheet: Meriones libycus. Mammals' Planet: Vs nº4, 04/2010. Retrieved May 2015. Available at: http://www.planet-mammiferes.

Bradley, R. D., \& Baker, R. J. (2001). A TEST OF THE GENETIC SPECIES CONCEPT: CYTOCHROME-b SEQUENCES AND MAMMALS. JOURNAL OF MAMMALOGY, 82(4), 14.

Bray, T. C., Alagaili, A. N., \& Bennett, N. C. (2014). A widespread problem: cryptic diversity in the Libyan jird. Zoological Studies, 53(1), 33. https://doi.org/10.1186/s40555-014-0033-3

Brito, P. H., \& Edwards, S. V. (2009). Multilocus phylogeography and phylogenetics using sequence-based markers. Genetica, 135(3), 439-455. https://doi.org/10.1007/s10709-0089293-3

Bruford, M. W., Hanotte, O., Brokfield, J. F. Y., \& Burke, T. (1992). Single-locus and multilocus DNA fingerprinting. In: (A.R. Hoelzel, ed.) Molecular genetic analysis of populations: a practical approach. Oxford University Press, New York. pp. 225-269.

Burnaby, T. P. (1966). Growth-Invariant Discriminant Functions and Generalized Distances. Biometrics, 22(1), 96. https://doi.org/10.2307/2528217

Cardini, A., \& Elton, S. (2009). The radiation of red colobus monkeys (Primates, Colobinae): morphological evolution in a clade of endangered African primates. Zoological Journal of the Linnean Society, 157(1), 197-224. https://doi.org/10.1111/j.1096-3642.2009.00508.x

Cardini, A., Jansson, A.-U., \& Elton, S. (2007). A geometric morphometric approach to the study of ecogeographical and clinal variation in vervet monkeys. Journal of Biogeography, 34(10), 1663-1678. https://doi.org/10.1111/j.1365-2699.2007.01731.x 
Cheesman, R. E., \& Hinton, M. A. C. (1924). LXII.-On the mammals collected in the Desert of Central Arabia by Major R. E. Cheesman. Annals and Magazine of Natural History, 14(83), 548-558. https://doi.org/10.1080/00222932408633158

Chevret, P., Veyrunes, F., \& Britton-Davidian, J. (2005). Molecular phylogeny of the genus Mus (Rodentia: Murinae) based on mitochondrial and nuclear data: MOLECULAR PHYLOGENY OF MUS. Biological Journal of the Linnean Society, 84(3), 417-427. https://doi.org/10.1111/j.1095-8312.2005.00444.x

Claude, J. (2008). Morphometrics with R. Universit de Montpellier II. ISEM, UMR 5554 CNRS. Laboratoire de Morphom trie. 2 place Eug ne Bataillon. 34095 Montpellier.

Claude, J., Pritchard, P., Tong, H., Paradis, E., \& Auffray, J.-C. (2004). Ecological correlates and evolutionary divergence in the skull of turtles: a geometric morphometric assessment. Systematic Biology, 53(6), 933-948. https://doi.org/10.1080/10635150490889498

Colangelo, P., Castiglia, R., Franchini, P., \& Solano, E. (2010). Pattern of shape variation in the eastern African gerbils of the genus Gerbilliscus (Rodentia, Muridae): Environmental correlations and implication for taxonomy and systematics. Mammalian Biology, 75(4), 302310. https://doi.org/10.1016/j.mambio.2009.05.001

Corbet, G. B. (1978). The Mammals of the Palaearctic region: a taxonomic review. British Museum of Natural History, Cornell Univ. Press, London.

Cortes, A., Zuleta, C., \& Rosenmann, M. (1988). Comparative water economy of sympatric rodents in a Chilean semi-arid habitat. Comparative Biochemistry and Physiology Part A: Physiology, 91(4), 711-714. https://doi.org/10.1016/0300-9629(88)90954-1

Darvish, J. (2009). Morphometric comparison of fourteen species of the genus Meriones Illiger, 1811 (Gerbillinae, Rodentia) from Asia and North Africa. Iranian Journal of Animal Biosystematic, 5, 59-77.

Darvish, J., Tarahomi, M., Dianat, M., Mohammadi, Z., Haddadian Shad, H., Moshtaghi, S. (2016). Biosystematics of three toed-Jerboas, Genus Jaculus (Erxleben, 1777) from Iran (Dipodidae, Rodentia). Iranian journal of Animal Biosystematic, 12, 123-139. doi: 10.22067/ijab.v12i1.55961 
Derricourt, R. (2005). Getting "Out of Africa": Sea Crossings, Land Crossings and Culture in the Hominin Migrations. Journal of World Prehistory, 19(2), 119-132. https://doi.org/10.1007/s10963-006-9002-z

Dianat, M., Aliabadian, M., Darvish, J., \& Akbarirad, S. (2012). Molecular phylogeny of the Iranian Plateau five-toed jerboa, Allactaga (Dipodidea: Rodentia), inferred from mtDNA. Mammalia, 77(1), 95-103. https://doi.org/10.1515/mammalia-2012-0011

Dianat, M., Darvish, J., Cornette, R., Aliabadian, M., \& Nicolas, V. (2017). Evolutionary history of the Persian Jird, Meriones persicus, based on genetics, species distribution modelling and morphometric data. Journal of Zoological Systematics and Evolutionary Research, 55(1), 29-45. https://doi.org/10.1111/jzs.12145

Dray, S., \& Dufour, A.-B. (2007). The ade4 Package: Implementing the Duality Diagram for Ecologists. Journal of Statistical Software, 22(1), 1-20. https://doi.org/10.18637/jss.v022.i04

Drummond, A. J., Rambaut, A., Shapiro, B., \& Pybus, O. G. (2005). Bayesian coalescent inference of past population dynamics from molecular sequences. Molecular Biology and Evolution, 22(5), 1185-1192. https://doi.org/10.1093/molbev/msi103

Drummond, Alexei J., Ho, S. Y. W., Phillips, M. J., \& Rambaut, A. (2006). Relaxed Phylogenetics and Dating with Confidence. PLOS Biology, 4(5), e88. https://doi.org/10.1371/journal.pbio.0040088

Drummond, Alexei J., \& Rambaut, A. (2007). BEAST: Bayesian evolutionary analysis by sampling trees. BMC Evolutionary Biology, 7(1), 214. https://doi.org/10.1186/1471-2148-7214

Ellerman, J. R. (1966). The Families and Genera of living Rodents. British Museum (Natural History). With a list of named forms (1758-1936) by R. W. Hayman and G. W. C. Holt. Volume I. Rodents other than Muridae.

Ellerman, J. R., \& Morrison-Scott, T. C. S. (1951). Checklist of Palearctic and Indian mammals, 1758 to 1946. Trustees of the British Museum (Natural History), London, 810 pp.

Etemad, E. (1978). Mammals of Iran. National Society of National Sources and Human Environment Protection Publications, Vol. I, Tehran 288.

Feldhamer, G. A., Drickamer, L. C., Vessey, S. H., Merritt, J. F \& Krajewski, C. (2007). Mammalogy: adaptation, diversity, ecology. JHU Press, Baltimore, Maryland 
Fernandes, C. A., Rohling, E. J., \& Siddall, M. (2006). Absence of post-Miocene Red Sea land bridges: biogeographic implications. Journal of Biogeography, 33(6), 961-966. https://doi.org/10.1111/j.1365-2699.2006.01478.x

Fouad, S. F. A., \& Sissakian, V. K. (2011). Tectonic and structural evolution of the Mesopotamia Plain. Iraqi Bulletin of Geology and Mining, 4, 33-46.

Gascuel, O. (1997). BIONJ: an improved version of the NJ algorithm based on a simple model of sequence data. Molecular Biology and Evolution, 14(7), 685-695. https://doi.org/10.1093/oxfordjournals.molbev.a025808

Goodwin, G. G., \& Expedition (1938), L. I. (1939). Five new rodents from the eastern Elburz Mountains and a new race of hare from Teheran. American Museum novitates; no. 1050. Retrieved from http://digitallibrary.amnh.org/handle/2246/4858

Gower, J. C. (1975). Generalized procrustes analysis. Psychometrika, 40(1), 33-51. https://doi.org/10.1007/BF02291478

Granjon, L. (2016). Meriones libycus. (errata version published in 2017) The IUCN Red List of Threatened Species 2016: e.T13164A115110005. http://dx.doi.org/10.2305/IUCN. UK. 2016-3.RLTS.T13164A22433926.en. Downloaded on 14 November 2017.

Gray, J. E. (1842). Descriptions of some new genera and fifty unrecorded species of Mammalia. The Annals and Magazine of Natural History; Zoology, Botany, and Geology, 10, $255-267$.

Gromov, I. M., Gureev, A. A., Novikov, G. A. et al. (1961). Mammals of the Fauna of USSR. Part 1. Moskva-Leningrad: Izdatel stvo Akademii Nauk SSSR. 638p. (in Russian).

Guindon, S., Dufayard, J.-F., Lefort, V., Anisimova, M., Hordijk, W., \& Gascuel, O. (2010). New Algorithms and Methods to Estimate Maximum-Likelihood Phylogenies: Assessing the Performance of PhyML 3.0. Systematic Biology, 59(3), 307-321. https://doi.org/10.1093/sysbio/syq010

Haddadian Shad, H., Darvish, J., \& Pouyan, E. R. (2016). Genetic Variation in Populations Of Field Mouse Apodemus Witherbyi (Thomas, 1902) (Rodentia: Muridae) in Iran Inferred from Mitochondrial Cytochrome B Gene Sequences and Geometric Morphometrics. Acta Zoologica Bulgarica, 68. Retrieved from http://profdoc.um.ac.ir/paper-abstract-1058674.html 
Hall, T. A. (1999). BioEdit: a user-friendly biological sequence alignment editor and analysis program for Windows 95/98.

Harrison, D. L., \& Bates, P. J. J. (1991). The Mammals of Arabia. Sec. Ed. Harrison Zoological Museum Publication, Kent, England.

Heptner, G. (1933). Notizen über die Gerbillinae (Mammalia, Muridae). V. Diagnosen von einer neuen Gattung und neun neuen Unterarten aus Turkestan. Von Wl. (Moskau). Mit zwei Abbildungen im Text.

Hervé, M (2018). RVAideMemoire: Testing and Plotting Procedures for Biostatistics. R package version 0.9-69-3. https://CRAN.R-project.org/package=RVAideMemoire

Hijmans, R. J. (2017). Geosphere: Spherical Trigonometry. R package version 1.5-7. https://CRAN.R-project.org/package=geosphere.

Huelsenbeck, J. P., \& Ronquist, F. (2001). MRBAYES: Bayesian inference of phylogenetic trees. Bioinformatics, 17(8), 754-755. https://doi.org/10.1093/bioinformatics/17.8.754

Ivanova, N. V., Dewaard, J. R., \& Hebert, P. D. N. (2006). An inexpensive, automationfriendly protocol for recovering high-quality DNA: TECHNICAL NOTE. Molecular Ecology Notes, 6(4), 998-1002. https://doi.org/10.1111/j.1471-8286.2006.01428.x

Kimura, M. (1980). A simple method for estimating evolutionary rates of base substitutions through comparative studies of nucleotide sequences. Journal of Molecular Evolution, 16(2), 111-120. https://doi.org/10.1007/BF01731581

Kimura, Y., M. T. Hawkins, M. M. McDonough, L. L. Jacobs, and L. J. Flynn. 2015. Corrected placement of Mus-Rattus fossil calibration forces precision in the molecular tree of rodents. Scientific Reports, 5:14444.

Kingdon, J., Happold, D., Butynski, T., Hoffmann, M., Happold, M., Kalina, J. (2013). Mammals of Africa, Volumes 1-6. Publisher: Bloomsbury.

Klingenberg, C. P. (1998). Heterochrony and allometry: the analysis of evolutionary change in ontogeny. Biological Reviews of the Cambridge Philosophical Society, 73(1), 79-123.

Koufos, G. D., Kostopoulos, D. S., \& Vlachou, T. D. (2005). Neogene/Quaternary mammalian migrations in eastern Mediterranean. 
Kryštufek, B., \& Vohralik, V. (2001). Mammals of Turkey and Cyprus: Introduction, checklist, Insectivora. Knjiznica Annales Majora, Koper, 140 pp.

Lay, D. M. (1972). The anatomy, physiology, functional significance and evolution of specialized hearing organs of gerbilline rodents. Journal of Morphology, 138(1), 41-120. https://doi.org/10.1002/jmor.1051380103

Librado, P., \& Rozas, J. (2009). DnaSP v5: a software for comprehensive analysis of DNA polymorphism data. Bioinformatics (Oxford, England), 25(11), 1451-1452. https://doi.org/10.1093/bioinformatics/btp187

Lichtenstein, H. (1823). Beschreibung vieler bisher unbekannter Arten von Saugethieren, Vogeln, Amphibien und Fischen herausgegeben. Verzeichnifs der Doubletten des zoologischen Museums. Der Konigl. Universitat zu Berlin nebst. Publication info: Berlin: In Commission beit. Trautwein. Contributed by: Smithsonian Libraries.

Macholán, M., Mikula, O., \& Vohralík, V. (2008). Geographic phenetic variation of two eastern-Mediterranean non-commensal mouse species, Mus macedonicus and M. cypriacus (Rodentia: Muridae) based on traditional and geometric approaches to morphometrics. Zoologischer Anzeiger - A Journal of Comparative Zoology, 247(1), 67-80. https://doi.org/10.1016/j.jcz.2007.07.003

Mantel, N. (1967). The detection of disease clustering and a generalized regression approach. Cancer Research, 27(2), 209-220.

Mason, M. J. (2016). Structure and function of the mammalian middle ear. I: Large middle ears in small desert mammals. Journal of Anatomy, 228(2), 284-299. https://doi.org/10.1111/joa.12313

Mendiburu, F. (2017). Agricolae: Statistical Procedures for Agricultural Research. R package version 1.2-8. https://CRAN.R-project.org/package=agricolae

Minarjkova, D. (2003). Quaternary palaeogeography of the northern part of Mesopotamia. Journal of Geological Sciences, 25, 5-30.

Monteiro, L. R. (1999). Multivariate Regression Models and Geometric Morphometrics: The Search for Causal Factors in the Analysis of Shape. Systematic Biology, 48(1), 192-199. https://doi.org/10.1080/106351599260526 
Montgelard, C., Bentz, S., Tirard, C., Verneau, O., \& Catzeflis, F. M. (2002). Molecular Systematics of Sciurognathi (Rodentia): The Mitochondrial Cytochrome b and 12S rRNA Genes Support the Anomaluroidea (Pedetidae and Anomaluridae). Molecular Phylogenetics and Evolution, 22(2), 220-233. https://doi.org/10.1006/mpev.2001.1056

Moritz, C. (1994). Applications of mitochondrial DNA analysis in conservation: A critical review. Molecular Ecology, 3, 401-411. doi: 10.1111/j.1365294X.1994.tb00080.x

Moriyama, H. (2013). Sexual dimorphism. In Teck press. pp 140.

Ndiaye, A., Chevret, P., Dobigny, G., \& Granjon, L. (2016). Evolutionary systematics and biogeography of the arid habitat-adapted rodent genus Gerbillus (Rodentia, Muridae): a mostly Plio-Pleistocene African history. Journal of Zoological Systematics and Evolutionary Research, 54(4), 299-317. https://doi.org/10.1111/jzs.12143

Nicolas, V., Schaeffer, B., Missoup, A. D., Kennis, J., Colyn, M., Denys, C., ... Laredo, C. (2012). Assessment of Three Mitochondrial Genes (16S, Cytb, CO1) for Identifying Species in the Praomyini Tribe (Rodentia: Muridae). PLOS ONE, 7(5), e36586. https://doi.org/10.1371/journal.pone.0036586

Ojeda, R. A., Borghi, C. E., Diaz, G. B., Giannoni, S. M., Mares, M. A., \& Braun, J. K. (1999). Evolutionary convergence of the highly adapted desert rodent Tympanoctomys barrerae (Octodontidae). Journal of Arid Environments, 41(4), 443-452. https://doi.org/10.1006/jare.1999.0496

Paradis, E., Claude, J., \& Strimmer, K. (2004). APE: Analyses of Phylogenetics and Evolution in R language. Bioinformatics, 20(2), 289-290. https://doi.org/10.1093/bioinformatics/btg412

Patten, M. A. (2015). Subspecies and the philosophy of science. The Auk, 132(2), 481-485. https://doi.org/10.1642/AUK-15-1.1

Pavlinov, I. Ya., \& Rossolimo, O. L. (1987). Sistematika mlekopitayushchikh SSSR [Systematics of the mammals of the USSR.]. Moscow University Press, Moscow, 282 pp. (in Russian).

Pavlinov, I. Y., \& Rogovin, K. A. (2000). Relation between size of pinna and of auditory bulla in specialized desert rodents. Journal of General Biology, 61, 87-101. 
Pavlinov, I. Y., Lissovsky, A. A., \& Obolenskaya, E. V. (2010). Geographic variation of skull traits in the Libyan jird, Meriones libycus (Rodentia: Gerbillinae), over its entire distribution area. Russian Journal of Theriology, 9(1), 19-26.

Posada, null, \& Crandall, null. (2001). Intraspecific gene genealogies: trees grafting into networks. Trends in Ecology \& Evolution, 16(1), 37-45.

Posada, D., \& Crandall, K. A. (2001). Selecting the best-fit model of nucleotide substitution. Systematic Biology, 50(4), 580-601.

Punzalan, D., \& Hosken, D. J. (2010). Sexual Dimorphism: Why the Sexes Are (and Are Not) Different. Current Biology, 20(22), R972-R973. https://doi.org/10.1016/j.cub.2010.09.067

R Development Core Team (2018). R: A Language and Environment for Statistical Computing. R Foundation for Statistical Computing, Vienna, Austria.URL http://www.Rproject.org/.

Rambaut., A, Suchard, M. A., Xie, D., \& Drummond, A. J. (2013). Tracer v1.5. Available from http://beast.bio.ed.ac.uk/Tracer.

Ranck, G. L. (1968). The Rodents of Libya: Taxonomy, Ecology, and Zoogeographical Relationships. Retrieved from http://repository.si.edu//handle/10088/10175

Rohlf, F. J. (1990). Rotational fit (Procrustes) methods. In: Rohlf F. J, Bookstein F. L., eds. Proceedings of the Michigan morphometrics workshop. Ann Arbor, MI: Museum of Zoology, University of Michigan, 227-236.

Rohlf, F. J. (2013). TPSdig, v. 2.17. Stony Brook, New York, Department of Ecology and Evolution, State University of New York. http://life.bio.sunysb.edu/morph.

Rohlf, F. J., \& Slice, D. (1990). Extensions of the Procrustes Method for the Optimal Superimposition of Landmarks. Systematic Zoology, 39(1), 40-59. https://doi.org/10.2307/2992207

Samuels, J. X. (2009). Cranial morphology and dietary habits of rodents. Zoological Journal of the Linnean Society, 156(4), 864-888. https://doi.org/10.1111/j.1096-3642.2009.00502.x

Setzer, H. W. (1961). The jirds (Mammalia, Rodentia) of Egypt. Journal of Egyptian Public Health Association. 36, 81-92. 
Siahsarvie, R., Auffray, J.-C., Darvish, J., Rajabi-Maham, H., Yu, H.-T., Agret, S., ... Claude, J. (2012). Patterns of morphological evolution in the mandible of the house mouse Mus musculus (Rodentia: Muridae). Biological Journal of the Linnean Society, 105(3), 635-647. https://doi.org/10.1111/j.1095-8312.2011.01821.x

Stoetzel, E., Cornette, R., Lalis, A., Nicolas, V., Cucchi, T., \& Denys, C. (2017). Systematics and evolution of the Meriones shawii/grandis complex (Rodentia, Gerbillinae) during the Late Quaternary in northwestern Africa: Exploring the role of environmental and anthropogenic changes. Quaternary Science Reviews, 164, 199-216. https://doi.org/10.1016/j.quascirev.2017.04.002

Tabatabaei Yazdi, F., \& Adriaens, D. (2011). Patterns of phenotypic skull variation in $M$. persicus (Rodentia: Muridae) in relation to geoclimatic conditions. Iranian Journal of Animal Biosystematic, 7, 129-142. doi: 10.22067/ijab.v7i2.25514

Tabatabaei Yazdi, F. T., Adriaens, D., \& Darvish, J. (2012). Geographic pattern of cranial differentiation in the Asian Midday Jird Meriones meridianus (Rodentia: Muridae: Gerbillinae) and its taxonomic implications. Journal of Zoological Systematics and Evolutionary Research, 50(2), 157-164. https://doi.org/10.1111/j.1439-0469.2011.00642.x

Tabatabaei Yazdi, F., \& Adriaens, D. (2013). Cranial variation in Meriones tristrami (Rodentia: Muridae: Gerbillinae) and its morphological comparison with Meriones persicus , Meriones vinogradovi and Meriones libycus: a geometric morphometric study. Journal of Zoological Systematics and Evolutionary Research, 51(3), 239-251. https://doi.org/10.1111/jzs.12020

Tabatabaei Yazdi, F. T., Adriaens, D., \& Darvish, J. (2014). Cranial phenotypic variation in Meriones crassus and M. libycus (Rodentia, Gerbillinae), and a morphological divergence in M. crassus from the Iranian Plateau and Mesopotamia (Western Zagros Mountains). European Journal of Taxonomy, O(88). https://doi.org/10.5852/ejt.2014.88

Tabatabaei Yazdi, F. T., Colangelo, P., \& Adriaens, D. (2015). Testing a long-standing hypothesis on the relation between the auditory bulla size and environmental conditions: a case study in two jird species (Muridae: Meriones libycus and M. crassus). Mammalia, 79(2). https://doi.org/10.1515/mammalia-2013-0043 
Tabatabaei Yazdi, F., \& Alhajeri, B. H. (2018). Sexual dimorphism, allometry, and interspecific variation in the cranial morphology of seven Meriones species -Gerbillinae, Rodentia. Hystrix, 29. Retrieved from http://profdoc.um.ac.ir/paper-abstract-1072817.html

Tamura, K., Dudley, J., Nei, M., \& Kumar, S. (2007). MEGA4: Molecular Evolutionary Genetics Analysis (MEGA) software version 4.0. Molecular Biology and Evolution, 24(8), 1596-1599. https://doi.org/10.1093/molbev/msm092

Thomas, O. (1912). XL.-On mammals from central Asia, collected by Mr. Douglas Carruthers. Annals and Magazine of Natural History, 9(52), 391-408. https://doi.org/10.1080/00222931208693148

Venables, W. N., \& Ripley, B. D. (2002). Modern Applied Statistics with S. Fourth Edition. Springer, New York. ISBN 0-387-95457-0, URL http://CRAN.R-project.org/package=MASS Wang, Y., Zhao, L.-M., Fang, F.-J., Liao, J.-C., \& Liu, N.-F. (2013). Intraspecific molecular phylogeny and phylogeography of the Meriones meridianus (Rodentia: Cricetidae) complex in northern China reflect the processes of desertification and the Tianshan Mountains uplift. Biological Journal of the Linnean Society, 110(2), 362-383. https://doi.org/10.1111/bij.12123

Webster, D. B., \& Webster, M. (1975). Auditory systems of Heteromyidae: functional morphology and evolution of the middle ear. Journal of Morphology, 146(3), 343-376. https://doi.org/10.1002/jmor.1051460304

Wright, S. (1943). Isolation by Distance. Genetics, 28(2), 114-138.

Zelditch, M. L., Swiderski, D. L., Sheets, H. D. (2012). Geometric morphometrics for biologists: a primer. (2nd ed.). Academic Press.

Zink, R. M., Groth, J. G., Vázquez-Miranda, H., \& Barrowclough, G. F. (2016). Geographic variation, null hypotheses, and subspecies limits in the California Gnatcatcher: A response to McCormack and Maley. The Auk, 133(1), 59-68. https://doi.org/10.1642/AUK-15-63.1

\section{Figures}




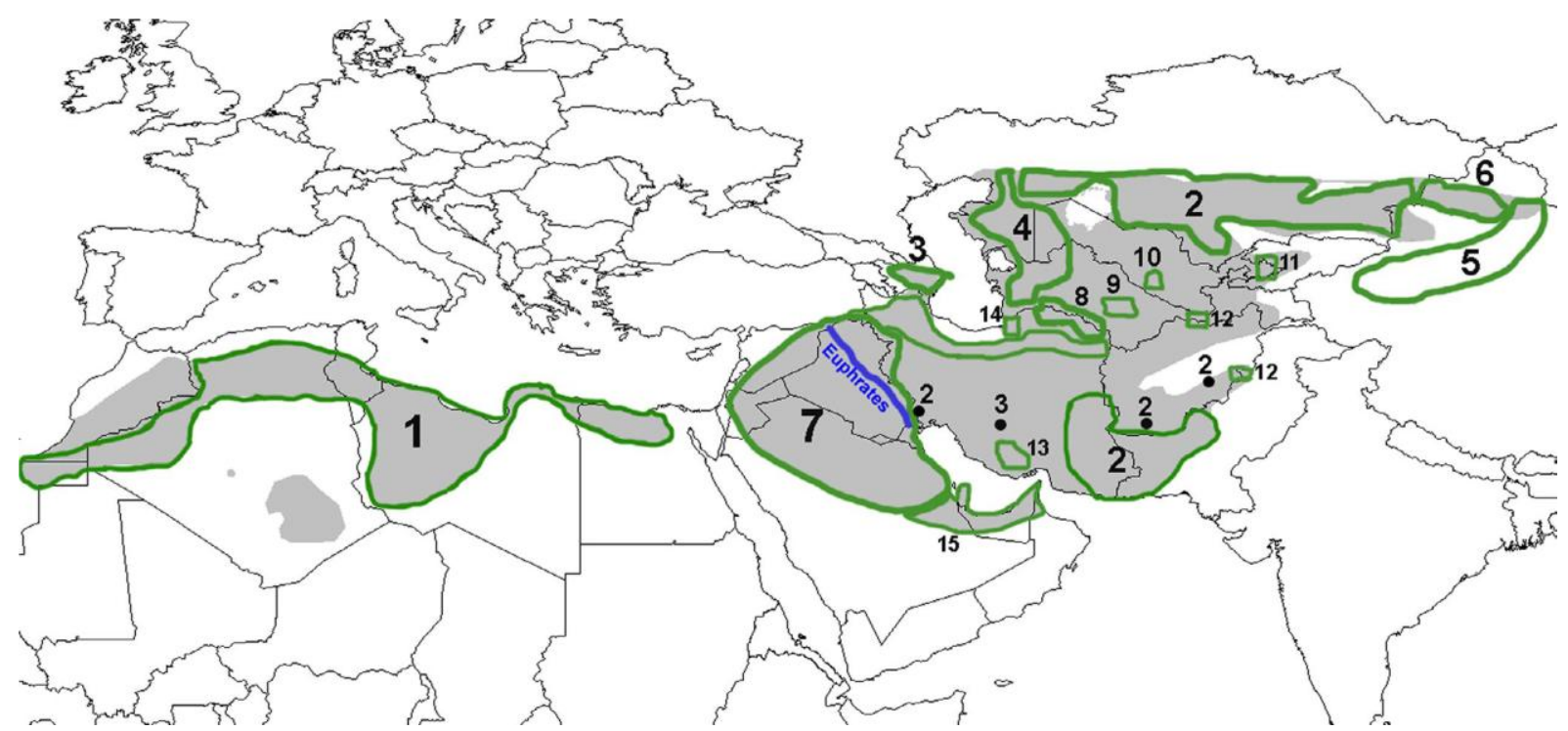

Figure 1. Map showing the actual geographical distribution of M. libycus (in light grey) and its subspecies (green drawing with numbers) based on Boudet (2010), Bray et al., (2014), Corbet (1978); Ellerman (1966), Ellerman \& Morrison-Scott (1951), Kingdon et al., (2013), Kryštufek \& Vohralik, 2001, Pavlinov et al., (2010) and Harrison \& Bates (1991). 1-M. l. libycus, 2-M. l. erythrourus, 3-M. l. caucasius, 4-M. l. eversmanni, 5-M. l. turfanensis 6-M. l. aquilo, 7-M. l. syrius, 8-M. l. maxeratis, 9-M. l. marginae 10-M. l. oxianus 11-M. l. sogdianus 12-M. l. afghanus 13-M. l. farsi 14-M. l. iranensis 15-M. l. arimalius. The blue line represents the Euphrates river.

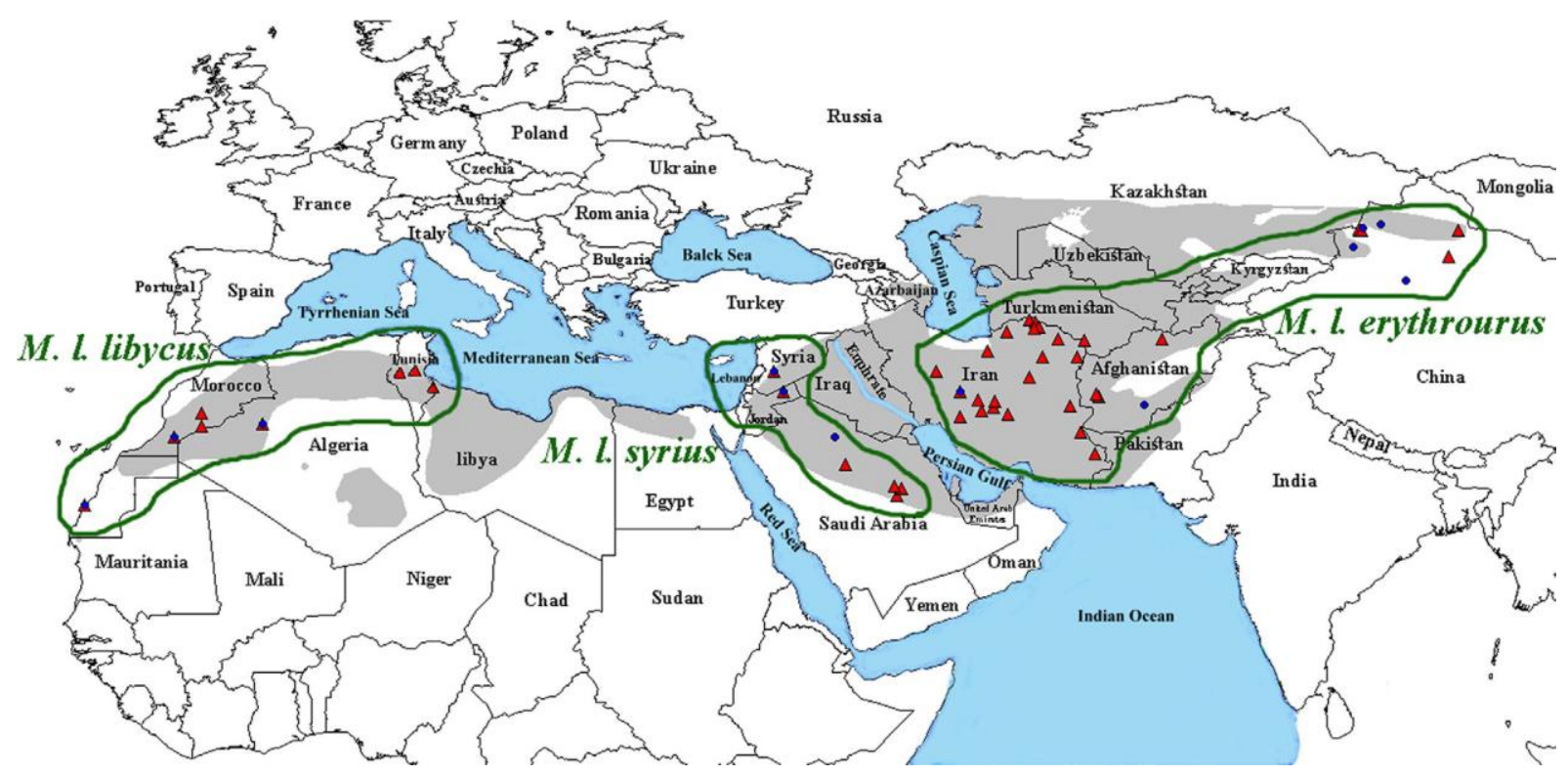

Figure 2. Map showing the sampling points of the specimens used in the molecular analysis (red triangles: Cytb; blue circles: Coxl) and three distinct subspecies, M. l. syrius, M. $l$. libycus and M. l. erythrourus corresponding to the main genetic lineages I, II and III, respectively. 


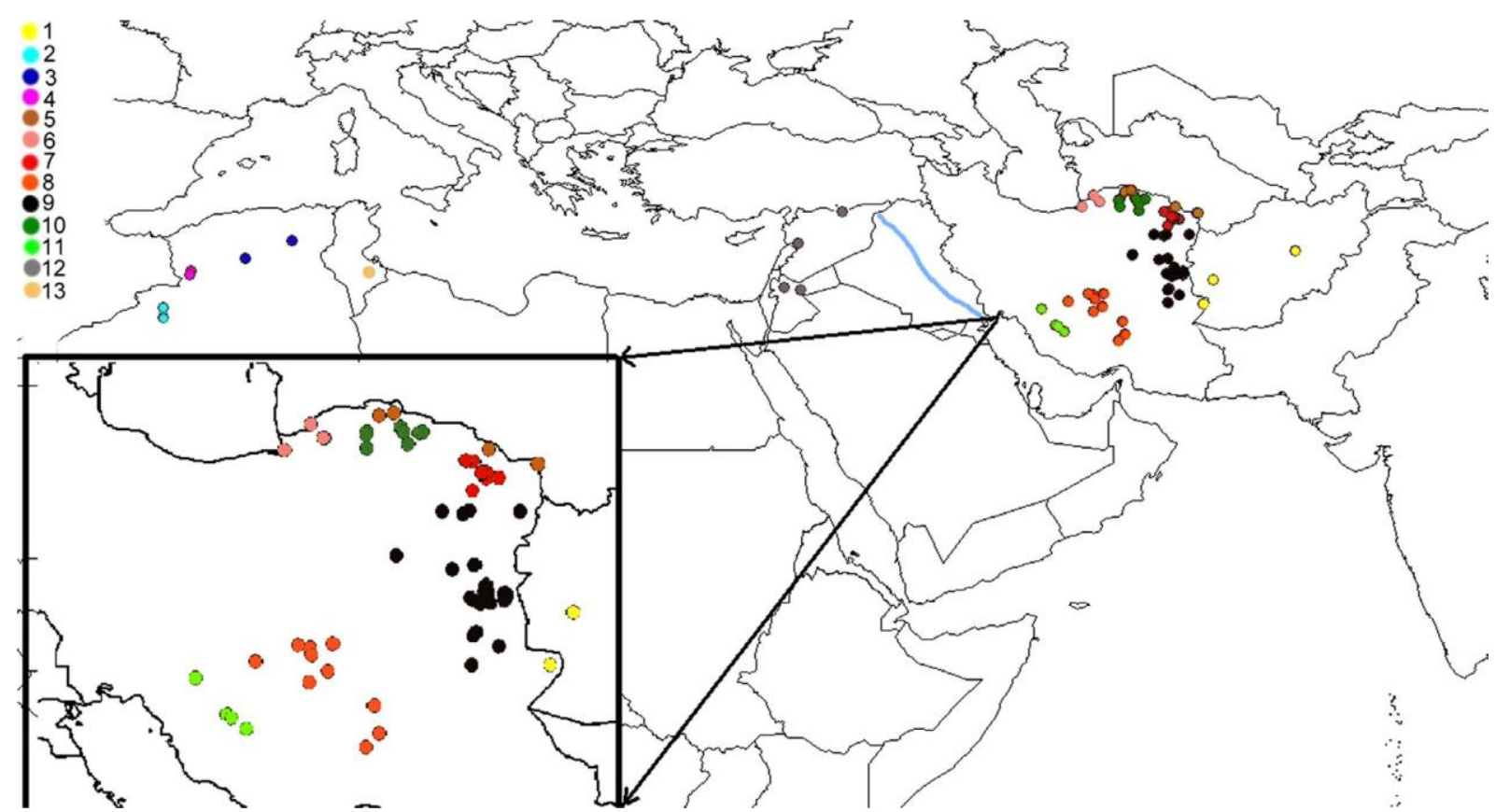

Figure 3. Map showing specimens in 13 groups used for geometric morphometric analysis.

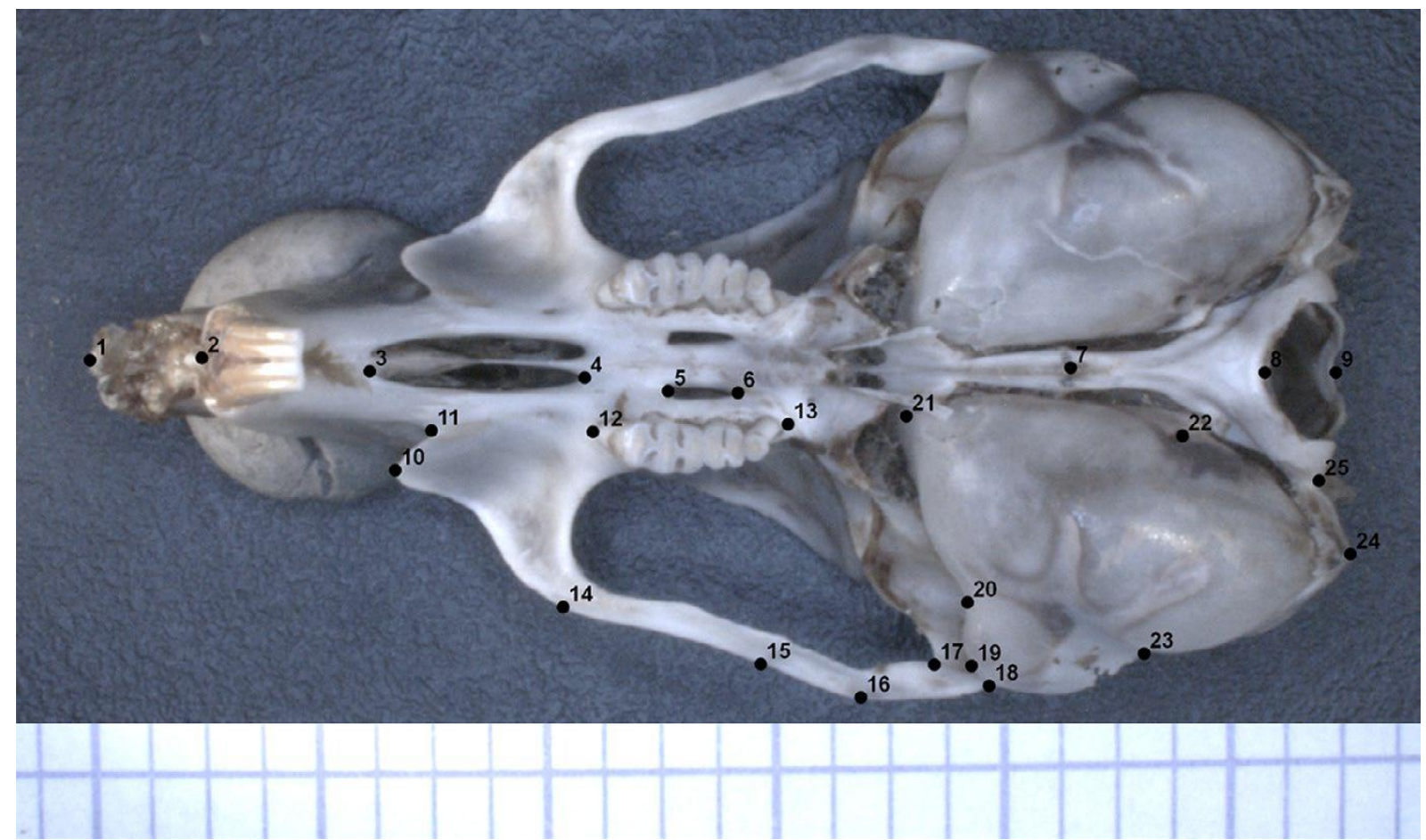

Figure 4. Anatomical location of the 25 landmarks on the ventral view of M. libycus skull used in this survey. 


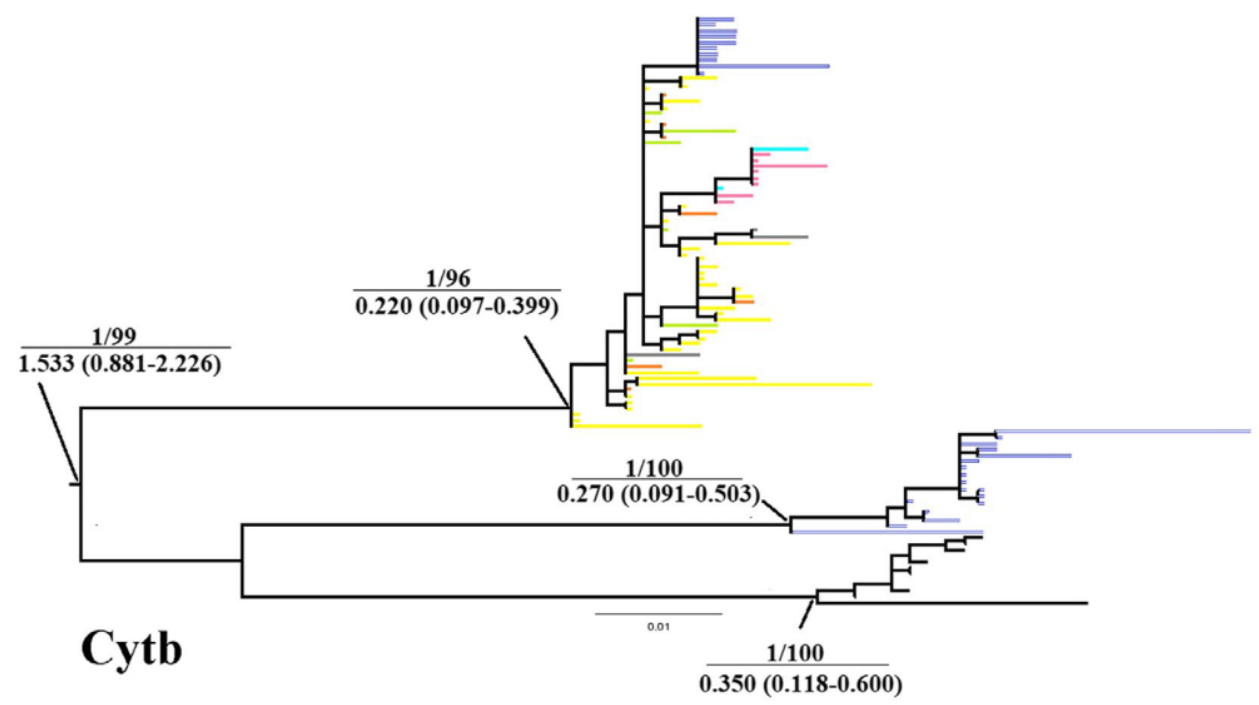

\section{Lineage III}

Afghanistan, Iran,

China, Tunisia

Lineage II

Tunisia, Morocco,

Algeria

Lineage I

Jordan, Saudi Arabia

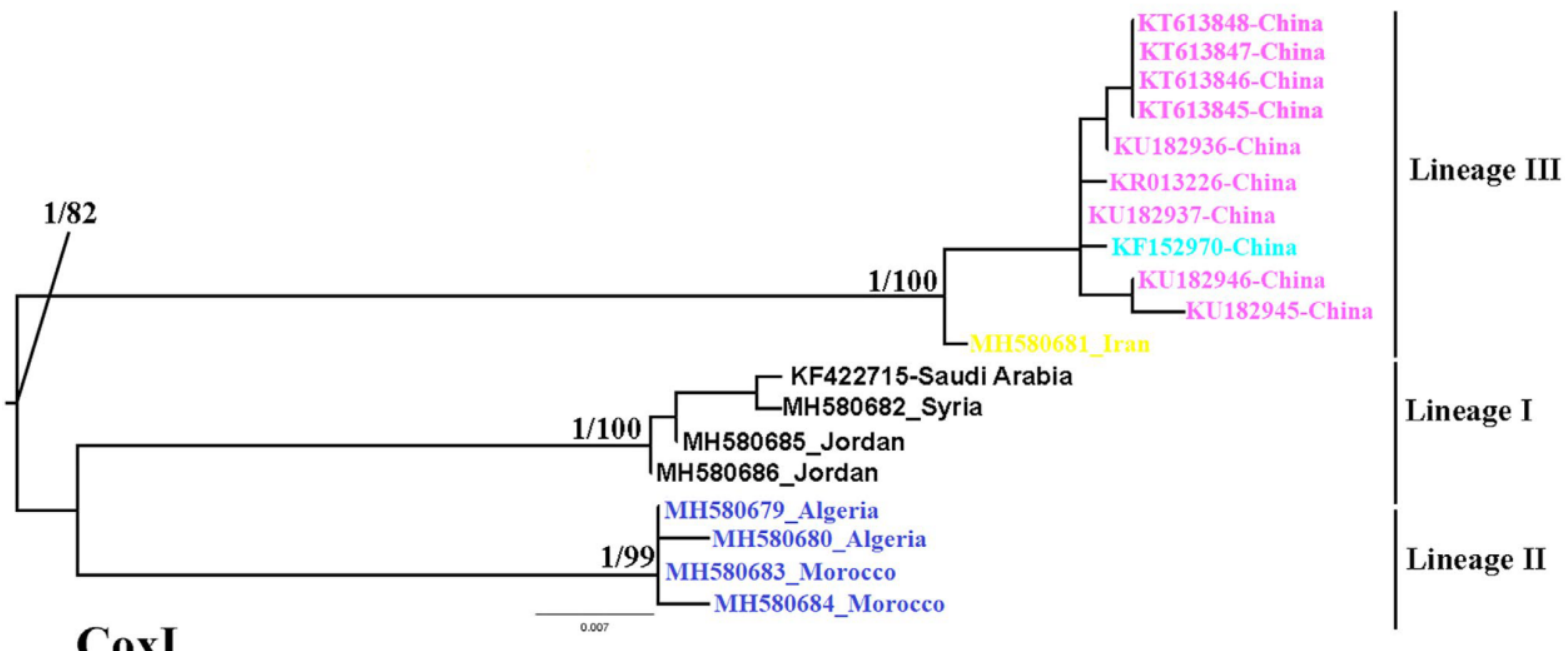

\section{CoxI}

Figure 5. Phylogeny recovered by the maximum-likelihood (ML) analysis for the Cytb and Coxl genes. Values upper the line indicate Bayesian posterior probabilities (given only if > 0.9) and ML bootstrap supports (given only if $>70 \%$ ) and values below the line indicate divergence time estimates with the highest density (HPD) interval containing $95 \%$ of the sampled values within brackets. To improve clarity, outgroups were removed. For details about specimens number, support values and geographic origins see supporting information Figure S2 and Figure S3. Colors indicate subspecies according to bibliographical data: gray: M. l. iranensis, yellow: no report, orange: M. l. maxeratis, blue: M. l. libycus, black: $M$. $l$. syrius, green: M. l. erythrourus, light blue: M. l. turfanensis, pink: M. l. aquilo. 

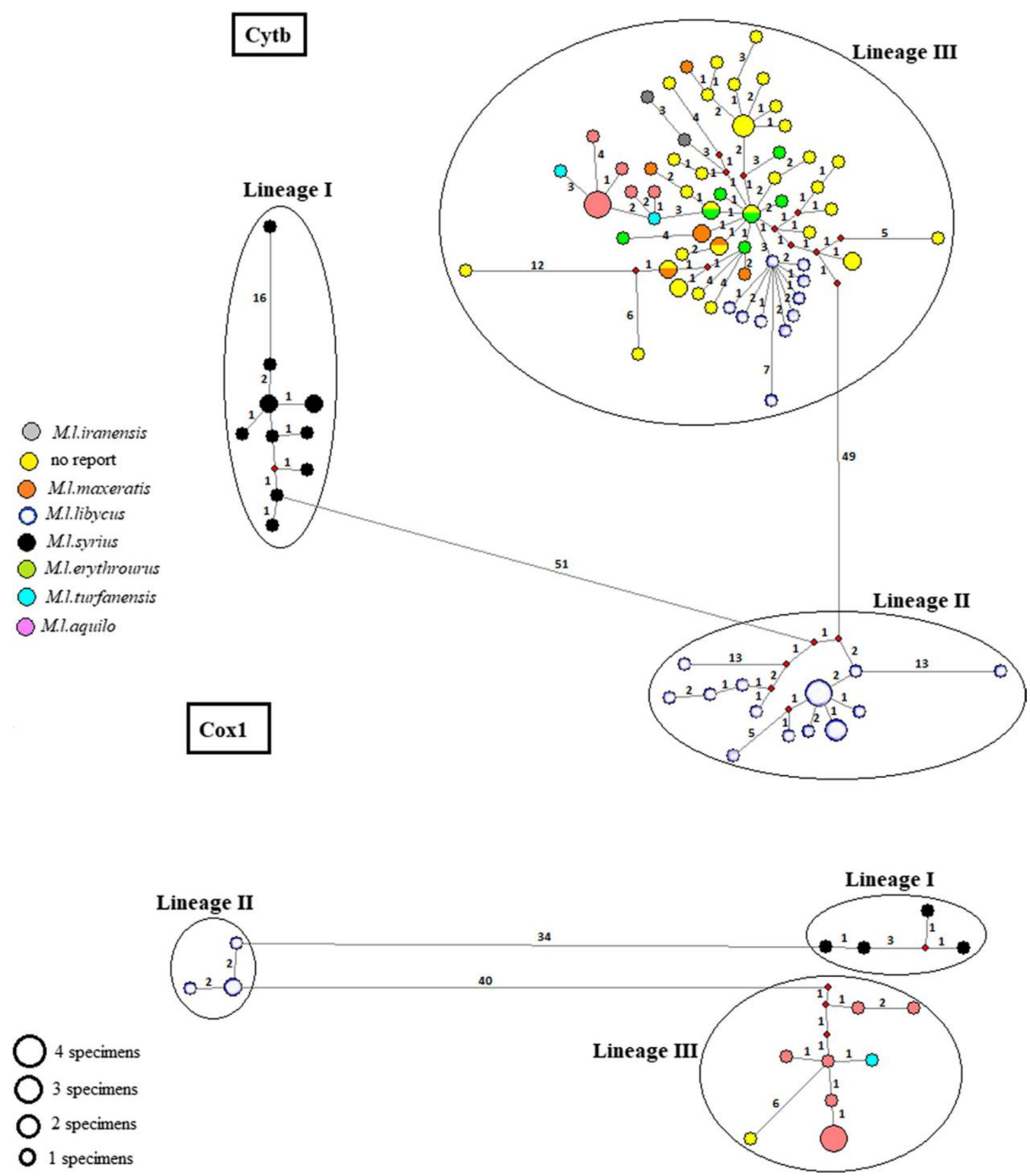

Figure 6. Median-joining network obtained for the Cytb and Coxl genes. Circle sizes are proportional to the number of similar haplotypes observed in the data set. The number of mutations between haplotypes is written. Colors indicate subspecies according to bibliographical data. 


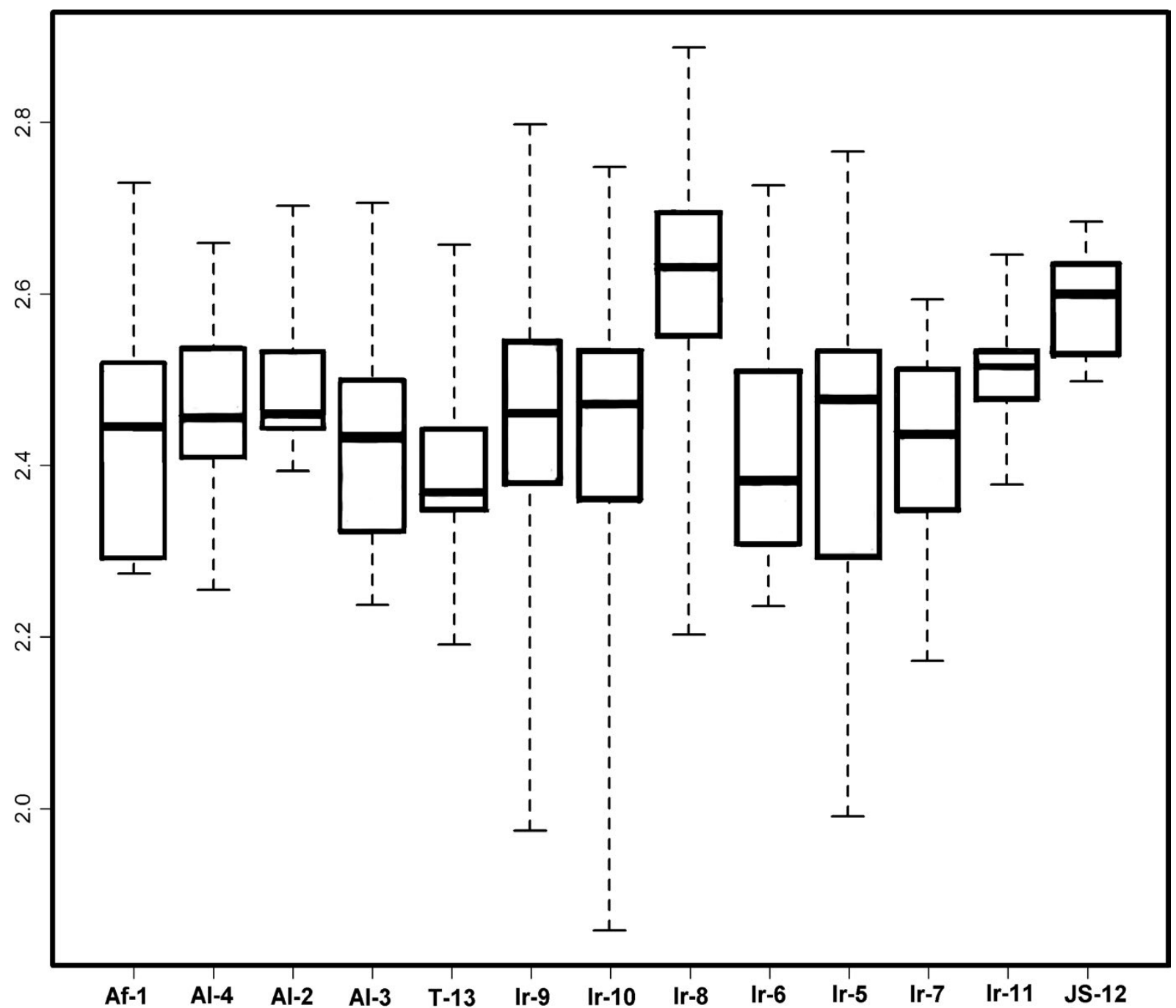

Figure 7. Box plots of the centroid size of the skull for different populations of Meriones libycus. Numbers indicate the 13 morphometric groups, and letters indicate country names $($ Af $=$ Afghanistan, $\mathrm{Al}=$ Algeria $, \mathrm{Ir}=\mathrm{Iran}, \mathrm{JS}=$ Jordan + Syria, $\mathrm{T}=$ Tunisia $)$. The whiskers represent the minimal and maximal values and the boxes show the first and the third quartiles.
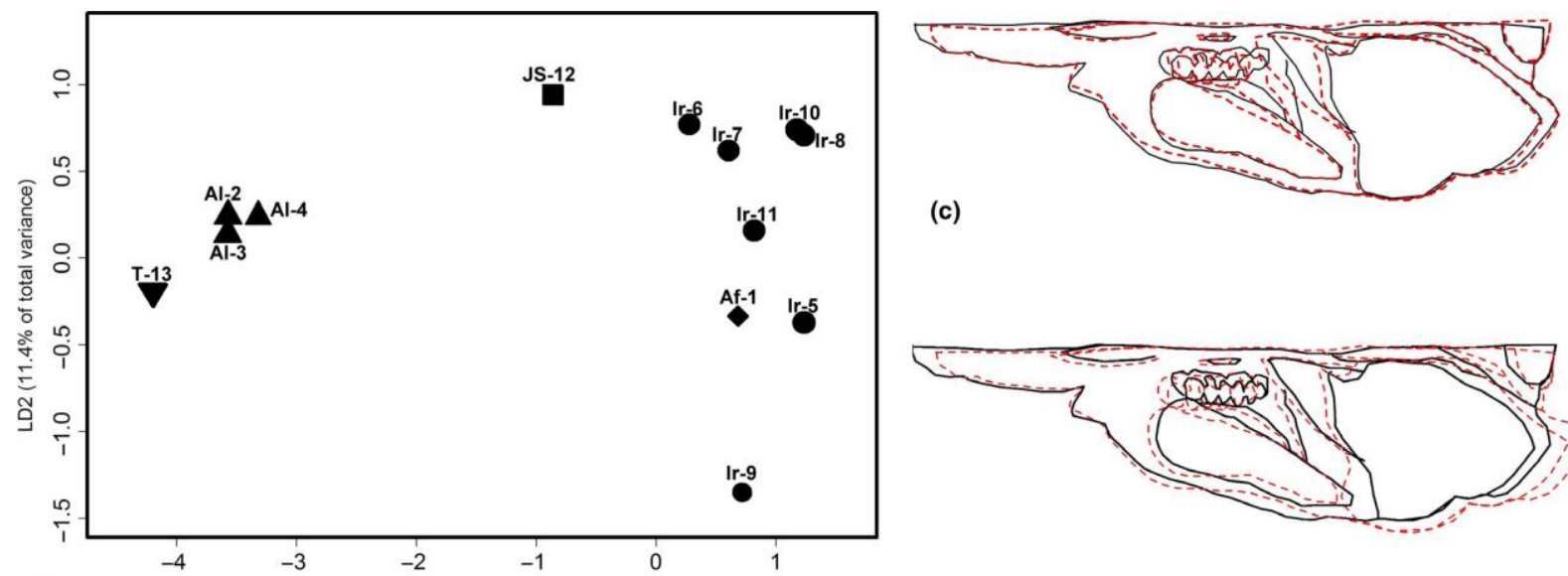

(a)

LD1 $(55.2 \%$ of total variance)

(b) 
Figure 8. a) Ordination of the 13 groups of Meriones libycus on the first two axes of the linear discriminant analyses on the ventral view of skull shape variability (55.2\% and $11.4 \%$ of total variance, respectively). Each point represents one group. Different symbols are used for distinct countries: circles $=$ Iran, diamond $=$ Afghanistan, square $=$ Syria and Jordan, upward triangles $=$ Algeria, downward triangle $=$ Tunisia. Numbers indicate the 13 morphometric groups, and letters indicate country names $(\mathrm{Af}=$ Afghanistan, $\mathrm{Al}=$ Algeria, $\mathrm{Ir}=\mathrm{Iran}, \mathrm{JS}=$ Jordan + Syria, $\mathrm{T}=$ Tunisia). b) Shape variation along the first discriminant axis. c) Shape variation along the second discriminant axis. Dashed line shows the skull shape for the extreme negative scores, and solid line for the extreme positive scores. 

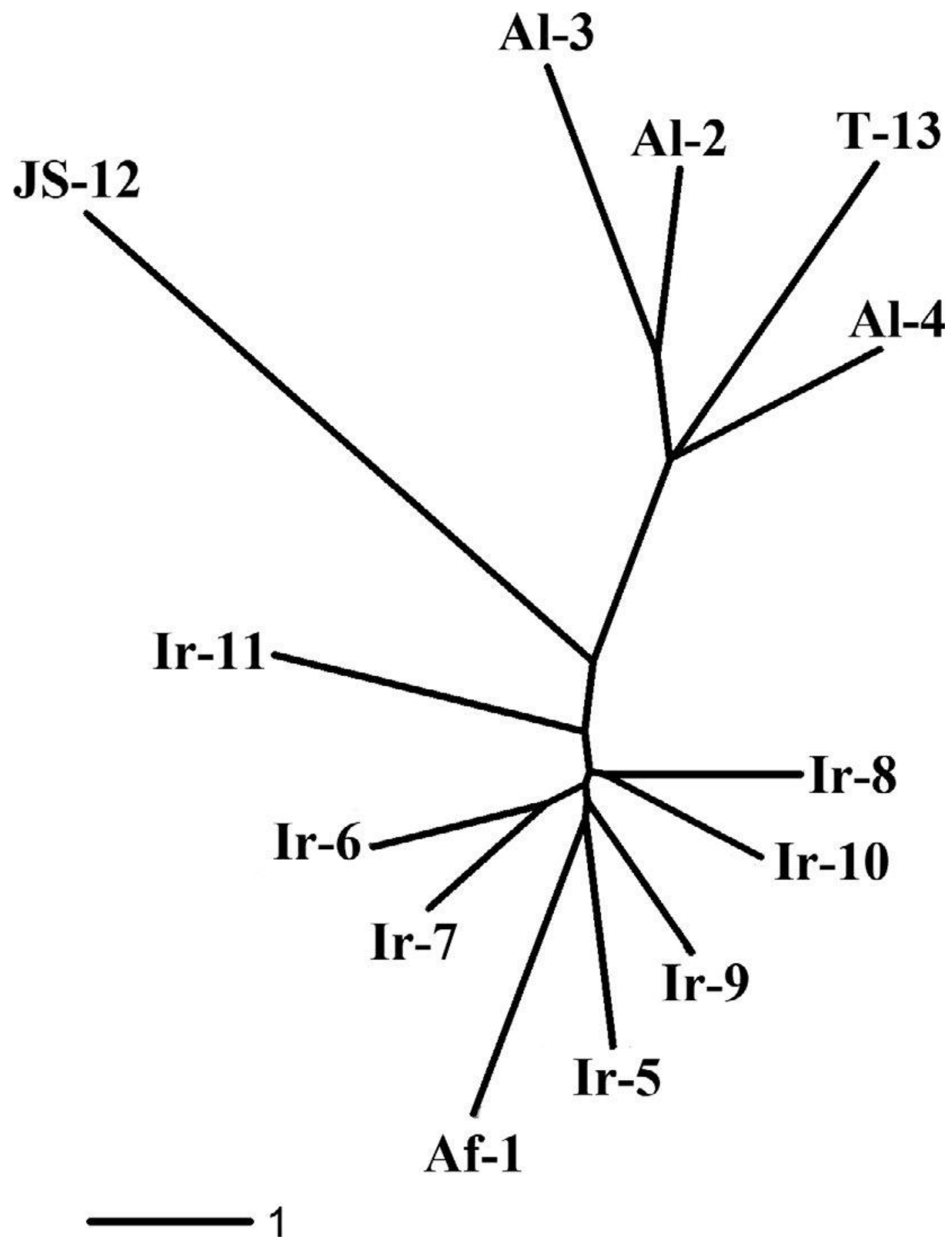

Figure 9. Neighbor-joining phenogram generated from the morphometric Procrustes distance matrix of the 13 Meriones libycus groups. Numbers indicate the 13 morphometric groups, and letters indicate country names $(\mathrm{Af}=$ Afghanistan, $\mathrm{Al}=$ Algeria, $\mathrm{Ir}=\mathrm{Iran}, \mathrm{JS}=\mathrm{Jordan}+$ Syria, $\mathrm{T}=$ Tunisia). 


\section{Tables}

Table 1. Diversity estimates for the main lineages of Meriones libycus identified in the phylogenetic analyses. $\mathrm{N}$, the number of specimens; $\mathrm{Np}$, the number of polymorphic sites; $\mathrm{Nh}$, the number of haplotypes; $\mathrm{Hd}$, haplotype diversity; Pi, nucleotide diversity; $\mathrm{k}$, average number of nucleotide differences.

\begin{tabular}{|c|l|l|l|l|l|c|}
\hline K & \multicolumn{1}{|c|}{ Pi } & Hd & Nh & Np & N & \\
\hline & & & & & & Cytb/CoxI \\
\hline $31.931 / 29.164$ & $0.04812 \pm 0.00587$ & $0.959 \pm 0.036$ & $81 / 15$ & $195 / 73$ & $100 / 19$ & All \\
& & & & & \\
\hline \multirow{2}{*}{$5.803 / 3.500$} & $0.00787 \pm 0.00296 /$ & $0.970 \pm 0.044 /$ & & & & Lineage I \\
\hline \multirow{2}{*}{$6.804 / 2.000$} & $0.00578 \pm 0.00138$ & $1.000 \pm 0.177$ & $10 / 4$ & $26 / 6$ & $12 / 4$ & \\
\hline \multirow{2}{*}{$7.743 / 3.527$} & $0.00923 \pm 0.00251 /$ & $0.941 \pm 0.041 /$ & & & & Lineage II \\
\hline & $0.00578 \pm 0.00138$ & $0.833 \pm 0.222$ & $13 / 3$ & $43 / 4$ & $18 / 4$ & \\
\hline
\end{tabular}

Table 2. Pairwise comparison of the centroid size mean between groups, using Tukey HSD post-hoc analysis. Bold numbers show the significant differences $(P<0.05)$. Numbers in the first row and column refer to the groups defined for geometric morphometric analyses.

\begin{tabular}{|c|c|c|c|c|c|c|c|c|c|c|c|}
\hline & 1 & 4 & 2 & 3 & 9 & 10 & 8 & 6 & 5 & 7 & 11 \\
\hline 4 & 1 & - & - & - & - & - & - & - & - & - & - \\
\hline 2 & 1 & 1 & - & - & - & - & - & - & - & - & - \\
\hline 3 & 1 & 1 & 0.9999 & - & - & - & - & - & - & - & - \\
\hline 9 & 1 & 1 & 0.9998 & 1 & - & - & - & - & - & - & - \\
\hline 10 & 1 & 1 & 0.9861 & 1 & 0.9999 & - & - & - & - & - & - \\
\hline 8 & 0.042 & 0.071 & 0.3449 & 0.2976 & 0.0006 & 0.0001 & - & - & - & - & - \\
\hline 6 & 1 & 0.998 & 0.9283 & 1 & 0.9928 & 1 & 0.0004 & - & - & - & - \\
\hline 5 & 1 & 0.9992 & 0.9545 & 1 & 0.9975 & 1 & 0.0009 & 1 & - & - & - \\
\hline 7 & 1 & 0.9998 & 0.9728 & 1 & 0.9993 & 1 & 0.0007 & 1 & 1 & - & - \\
\hline
\end{tabular}




\begin{tabular}{|c|c|c|c|c|c|c|c|c|c|c|c|c|}
\hline 11 & 0.9999 & 1 & 1 & 0.9996 & 0.9994 & 0.988 & 0.9177 & 0.9439 & 0.9609 & 0.9755 & - & \\
\hline 12 & 0.8786 & 0.8168 & 0.9555 & 0.8115 & 0.6696 & 0.479 & 1 & 0.3547 & 0.3953 & 0.4357 & 0.9957 & \\
\hline 13 & 1 & 0.994 & 0.8889 & 1 & 0.9812 & 0.9999 & $\mathbf{0 . 0 0 0 5}$ & 1 & 1 & 1 & 9144 & 0 \\
\hline
\end{tabular}

Table 3. Pairwise comparison of the cranial shape between the groups, using pairwise permutation MANOVA with $10 \mathrm{~K}$ permutations. Bold numbers show the significant differences $(P<0.05)$. Numbers in the first row and column refer to the groups defined for geometric morphometric analyses.

\begin{tabular}{|c|c|c|c|c|c|c|c|c|c|c|c|}
\hline 1 & 4 & 2 & 3 & 9 & 10 & 8 & 6 & 5 & 7 & 11 & 1 \\
\hline 0.00029 & - & - & - & - & - & - & - & - & - & - & \\
\hline 0.00029 & 0.22459 & - & - & - & - & - & - & - & - & - & \\
\hline 0.00446 & 0.03763 & 0.86211 & - & - & - & - & - & - & - & - & \\
\hline 0.3644 & \begin{tabular}{|l|l}
0.00029 \\
\end{tabular} & 0.00029 & \begin{tabular}{|l|l|}
0.00115 \\
\end{tabular} & - & - & - & - & - & - & - & \\
\hline 0.32834 & \begin{tabular}{|l|l|}
0.00029 \\
\end{tabular} & 0.00029 & \begin{tabular}{|l|l|}
0.00148 \\
\end{tabular} & \begin{tabular}{|l|l|}
0.00134 \\
\end{tabular} & - & - & - & - & - & - & \\
\hline 0.07208 & \begin{tabular}{|l|l|}
0.00029 \\
\end{tabular} & $\mathbf{0 . 0 0 0 2 9}$ & $\mid 0.00029$ & \begin{tabular}{|l|l|l|}
0.0029 \\
\end{tabular} & \begin{tabular}{|l|l|}
0.00697 \\
\end{tabular} & - & - & - & - & - & \\
\hline 0.22529 & \begin{tabular}{|l|l|l|}
0.00029 \\
\end{tabular} & 0.00029 & (0.00029 & 0.00285 & \begin{tabular}{|l|l|}
0.01101 \\
\end{tabular} & \begin{tabular}{|l|l|}
0.00148 \\
\end{tabular} & - & - & - & - & \\
\hline 0.85923 & $\mid 0.00029$ & 0.00029 & 0.00175 & \begin{tabular}{|l}
0.13919 \\
\end{tabular} & 0.12454 & 0.05587 & 0.05261 & - & - & - & \\
\hline 0.21276 & 0.00029 & 0.00029 & 0.0016 & 0.00514 & O.02028 & 0.0049 & 0.79295 & 0.04935 & - & - & \\
\hline 0.16902 & 0.00029 & 0.00052 & $\begin{array}{ll}0.0131 \\
\end{array}$ & 0.07415 & 0.3702 & 0.66304 & 0.05316 & 0.48671 & 0.15776 & - & \\
\hline 0.012 & 0.0016 & 0.00075 & 0.00971 & 0.00029 & 0.00764 & 0.00644 & 0.00052 & 0.00589 & 0.00095 & 0.00983 & \\
\hline 0.00029 & 0.00052 & $\mathbf{0 . 0 2 5 0 7}$ & $\mid 0.01704$ & \begin{tabular}{|l|l}
0.00029 \\
\end{tabular} & \begin{tabular}{|l|l|}
0.00029 \\
\end{tabular} & \begin{tabular}{|l|l|}
0.00029 \\
\end{tabular} & \begin{tabular}{|l|l|}
0.00029 \\
\end{tabular} & \begin{tabular}{|l|l|}
0.00029 \\
\end{tabular} & \begin{tabular}{|l|l|}
0.00029 \\
\end{tabular} & \begin{tabular}{|l|l|}
0.00029 \\
\end{tabular} & \\
\hline
\end{tabular}

\section{Supporting Information}

Figure S1. Divergence dating analysis based on the Cytb gene. Nodes show medians of times to most recent common ancestor (MRCA), node bars indicate 95\% HPD intervals. Latin numbers in red indicate the 6 fossil calibration points constrains used in this study. 1: the Gerbillinae-Deomyinae split, 2: the Lophuromys-Acomys-Deomys split, 3: the Meriones- 
Psammomys-Rhombomys split, 4: the Gerbillus-Sekeetamys split, 5: the GerbilliscusDesmodillus split, 6: the oldest fossil of Gerbilliscus.

Figure S2. Phylogeny recovered by the maximum-likelihood (ML) analysis for the Cytb gene - Zoom on lineage III. Bayesian posterior probabilities (given only if > 0.9) and ML bootstrap supports (given only if $>70 \%$ ).

Figure S3. Phylogeny recovered by the maximum-likelihood (ML) analysis for the Cytb gene - Zoom on lineages I and II. Bayesian posterior probabilities (given only if >0.9) and ML bootstrap supports (given only if $>70 \%$ ).

Figure S4. Scatterplot and regression line of Procrustes morphometric distances versus geographical distances $(\mathrm{km})$. Each point shows a distance between pairs of two studied groups. Blue points are the distances of central lineage to the other groups.

Figure S5. Scatterplot and regression line of $C y t b$ genetic distances versus geographical distances $(\mathrm{km})$. Each point shows a distance between pairs of two studied groups. Blue points are the distances of central lineage to the other groups.

Figure S6. Scatterplot and regression line of Procrustes morphometric distances versus $C y t b$ genetic distances. Each point shows a distance between pairs of two studied groups. Blue points are the distances of central lineage to the other groups.

Table S1. List of specimens used in this study, with voucher numbers, accession numbers, localities of collection, morphometric and molecular data sets and groups. ZMFUM: Zoology Museum of Ferdowsi University of Mashhad, Mashhad, Iran. MNHN: French National Museum of Natural History, Paris, France. PMS: Slovenian Museum of Natural History. CN: clustering number. GM: Geometric Morphometric analysis. GL: genetic lineage. Bold accession numbers represent the sequences acquired in the present study.

Table S2. Definition and numbering of the landmarks (LM) digitized on the ventral view. 
Dataset 1. Alignments used for phylogenetic analysis of $C y t b$.

Dataset 2. Alignments used for phylogenetic analysis of Coxl.

Appendices.

Appendix 1. List of specimens of Meriones libycus used in molecular analysis, with voucher numbers, localities of collection and Genbank accession numbers. ZMFUM: Zoology Museum of Ferdowsi University of Mashhad, Mashhad, Iran. MNHN: French National Museum of Natural History, Paris, France. PMS: Slovenian Museum of Natural History. Bold accession numbers represent the sequences acquired in the present study.

Appendix 2. Collection numbers of morphologically analyzed specimens of Meriones libycus. 